\title{
Specific immune modulation of experimental colitis drives enteric alpha-synuclein accumulation and triggers age-related Parkinson-like brain pathology
}

\section{Stefan Grathwohl}

Roche Pharma Schweiz AG

Emmanuel Quansah

VARI: Van Andel Research Institute

Nazia Maroof

Roche Pharma AG

Jennifer A Steiner

VARI: Van Andel Research Institute

Liz Spycher

Roche Pharma AG

Fethallah Benmansour

Roche Pharma AG

Gonzalo Duran-Pacheco

Roche Pharma AG

Juliane Siebourg-Polster

Roche Pharma AG

Krisztina Oroszlan-Szovik

Roche Pharma AG

Helga Remy

Roche Pharma AG

Markus Haenggi

Roche Pharma AG

Marc Stawiski

Roche Pharma AG

Matthias Selhausen

Roche Pharma AG

Pierre Maliver

Roche Pharma AG

Andreas Wolfert

Roche Diagnostics $\mathrm{GmbH}$

Thomas Emrich 
Roche Diagnostics GmbH

\section{Zachary Madaj}

VARI: Van Andel Research Institute

\section{Arel Su}

Roche Pharma AG

\section{Martha L Escobar Galvis}

VARI: Van Andel Research Institute

\section{Christoph Mueller}

University of Berne Institute of Pathology: Universitat Bern Institut fur Pathologie

\section{Annika Herrmann}

Roche Pharma AG

\section{Patrik Brundin}

VARI: Van Andel Research Institute

Markus Britschgi ( $\square$ markus.britschgi@roche.com )

Hoffmann-La Roche https://orcid.org/0000-0001-6151-4257

\section{Research article}

Keywords: Parkinson's disease, colitis, enteric nervous system, peripheral inflammation, a-synuclein 92 pathology, neurodegeneration, translational mouse model

Posted Date: November 3rd, 2020

DOI: https://doi.org/10.21203/rs.3.rs-100199/v1

License: (c) (i) This work is licensed under a Creative Commons Attribution 4.0 International License.

Read Full License 
Specific immune modulation of experimental colitis drives enteric alpha-synuclein accumulation

4 Stefan Grathwohl ${ }^{1}$, Emmanuel Quansah ${ }^{2}$, Nazia Maroof ${ }^{1}$, Jennifer A. Steiner ${ }^{2}$, Liz Spycher $^{1}$, Fethallah

5 Benmansour ${ }^{3}$, Gonzalo Duran-Pacheco ${ }^{4}$, Juliane Siebourg-Polster ${ }^{4}$, Krisztina Oroszlan-Szovik ${ }^{1}$, Helga

6 Remy $^{1}$, Markus Haenggi ${ }^{1}$, Marc Stawiski ${ }^{1}$, Matthias Sehlhausen ${ }^{4}$, Pierre Maliver ${ }^{4}$, Andreas Wolfert ${ }^{5}$,

7 Thomas Emrich ${ }^{5}$, Zachary Madaj ${ }^{2}$, Arel Su${ }^{4}$, Martha L. Escobar Galvis ${ }^{2}$, Christoph Mueller ${ }^{6}$, Annika

8 Herrmann $^{4}$, Patrik Brundin ${ }^{2 *}$, and Markus Britschgi ${ }^{1 *}$

9

$10{ }^{1}$ Roche Pharma Research and Early Development, Neuroscience and Rare Diseases Research, Roche 11 Innovation Center Basel, F. Hoffmann-La Roche Ltd, Grenzacherstrasse 124, Basel, Switzerland

$12{ }^{2}$ Center for Neurodegenerative Science, Van Andel Research Institute, 333 Bostwick Ave. NE, Grand 13 Rapids, MI, USA

$14{ }^{3}$ Roche Pharma Research and Early Development, pREDi, Roche Innovation Center Basel, F.

15 Hoffmann-La Roche Ltd, Grenzacherstrasse 124, Basel, Switzerland

$16 \quad{ }^{4}$ Roche Pharma Research and Early Development, Pharmaceutical Sciences, Roche Innovation

17 Center Basel, F. Hoffmann-La Roche Ltd, Grenzacherstrasse 124, Basel, Switzerland

$18 \quad{ }^{5}$ Roche Pharma Research and Early Development, Pharmaceutical Sciences, Roche Innovation Center

19 Munich, Roche Diagnostics GmbH, Nonnenwald 2, Penzberg, Germany

$20{ }^{6}$ Institute of Pathology, University of Bern, Murtenstrasse 31, Bern, Switzerland

Corresponding authors:

* Markus Britschgi, Roche Pharma Research and Early Development, Neuroscience and Rare

Diseases Research, Roche Innovation Center Basel, F. Hoffmann-La Roche Ltd, Grenzacherstrasse 124, 4070 Basel, Switzerland

Tel: +41616879116

Email: markus.britschgi@roche.com

* Patrik Brundin, Van Andel Institute, 333 Bostwick Ave. NE, Grand Rapids, MI 49503, USA.

Tel: +1 616.234.5312

Email: patrik.brundin@vai.org 
40 Stefan Grathwohl, S.Grathwohl@gmx.de

41 Emmanuel Quansah, Emmanuel.Quansah@vai.org

42 Nazia Maroof, naziamaroof@yahoo.co.uk

43 Jennifer Steiner, Jennifer.Steiner@vai.org

$44 \quad$ Liz Spycher, liz.spycher@gmail.com

$45 \quad$ Fethallah Benmansour, fethallah.benmansour@roche.com

46 Gonzalo Duran-Pacheco, gonzalo_christian.duran_pacheco@roche.com

47 Juliane Siebourg-Polster, juliane.siebourg-polster@roche.com

48 Krisztina Oroszlan-Szovik, krisztina.oroszlan@bluewin.ch

49 Helga Remy, helga.remy@roche.com

50 Markus Haenggi, markus.haenggi@sunrise.ch

51 Marc Stawiski, marc.stawiski@gmail.com

52 Matthias Selhausen, matthias.selhausen@roche.com

53 Pierre Maliver, pierre.maliver@roche.com

54 Andreas Wolfert, andreas.wolfert@roche.com

55 Thomas Emrich, thomas.emrich@roche.com

56 Zachary Madaj, Zachary.Madaj@vai.org

57 Arel Su, arel.su@roche.com

58 Martha Escobar, Martha.Escobar@vai.org

59 Christoph Mueller, christoph.mueller@pathology.unibe.ch

60 Annika Herrmann, annika@bridgepathology.com

61 Patrik Brundin, Patrik.Brundin@vai.org

62 Markus Britschgi, markus.britschgi@roche.com 


\section{Abstract}

Background: Intraneuronal accumulation of $\alpha$-synuclein $(\alpha \operatorname{Syn})$ is key in Parkinson's disease (PD) pathogenesis. The pathogenic process is suggested to begin in the enteric nervous system decades before diagnosis of PD and then propagate into the brain. The triggers for these events are unclear but, in some patients, colitis might play a critical role.

Methods: We administered lipopolysaccharide (LPS) or dextran sulfate sodium (DSS) to assess the effect of different types of experimental colitis on $\alpha$ Syn accumulation in the gut of $\alpha$ Syn transgenic and wild type mice and quantified local gene expression by RT-PCR and level of $\alpha$ Syn accumulation by immunofluorescence imaging. Immune modulation during the DSS colitis paradigm in the $\alpha$ Syn transgenic mice included genetic ablation of Cx3cr1 or treatment with recombinant IL-10. To determine long-term effects of experimental colitis, we induced DSS colitis in young aSyn transgenic mice and aged them under normal conditions up to nine or 21 months before analyzing their brains by immunohistochemistry. In vivo experiments were performed in randomized cohorts. Blinded experimenters performed image analysis and statistical analysis depended on data type (i.e., Student's t-test, ANOVA, mixed-effects model).

Results: We demonstrate that mild sustained or one strong insult of experimental DSS colitis triggers $\alpha$ Syn accumulation in the submucosal plexus of wild type and $\alpha$ Syn transgenic mice, while short-term mild DSS experimental colitis or inflammation induced by LPS does not have such an effect. Lack of macrophage-related Cx3cr1-signalling during DSS colitis increases accumulation of $\alpha$ Syn in the colonic submucosal plexus of $\alpha$ Syn transgenic mice while systemic treatment with immunedampening IL-10 ameliorates this phenomenon. Additionally, DSS colitis-induced $\alpha$ Syn accumulation in young $\alpha$ Syn transgenic mice persists for months and is exacerbated by lack of $\mathrm{Cx} 3 \mathrm{cr} 1$-signaling. Remarkably, experimental colitis at three months of age exacerbates the accumulation of aggregated phospho-Serine 129 aSyn in the midbrain (including the substantia nigra), in 21- but not 9-month-old $\alpha$ Syn transgenic mice. This increase in midbrain $\alpha$ Syn accumulation is accompanied by the loss of tyrosine hydroxylase-immunoreactive nigral neurons. 
89 Conclusions: Our data suggest that specific types of intestinal inflammation, mediated by

90 monocyte/macrophage signaling, could play a critical role in the initiation and progression of PD.

91

92 Keywords: Parkinson's disease; colitis; enteric nervous system; peripheral inflammation; $\alpha$-synuclein

93 pathology; neurodegeneration; translational mouse model

94 


\section{Background}

Parkinson's disease (PD) is a progressively debilitating neurodegenerative disease affecting $1 \%$ of the population above 60 years [1]. Typical symptoms are motor impairments including muscle rigidity, tremor, and bradykinesia. Neuropathologically, PD is hallmarked by loss of dopaminergic neurons in the substantia nigra $(\mathrm{SN})$, a concomitant reduction of striatal dopaminergic signaling [2], and the presence of intraneuronal inclusions called Lewy bodies and neurites [3]. Lewy pathology is enriched in $\alpha$-synuclein ( $\alpha \mathrm{Syn})$, a presynaptic protein that tends to aggregate and become phosphorylated under pathological conditions [2]. Rare point mutations in $\alpha$ Syn and gene multiplications also cause familial forms of PD and related neurological conditions, and certain single nucleotide polymorphisms close to the $\alpha$ Syn gene (SNCA) locus are associated with increased risk for sporadic PD [4]. These findings make $\alpha$ Syn a focal point of biomarker and drug development programs for PD.

Several years before the first appearance of motor symptoms, many patients exhibit a variety of nonmotor symptoms including constipation, sleep disorder, depression, and hyposmia [5-7]. Indeed, cooccurrence of some of these non-motor symptoms is coupled to elevated PD risk [8-11]. Constipation is an important non-motor feature of prodromal PD, with $28-61 \%$ of patients having exhibited gastrointestinal dysfunction for several years during the prodrome $[7,10,12]$. Notably, $\alpha$ Synimmunoreactive inclusions have been found in neurons of the submucosal plexus in people with PD $[3,13]$. Taken together, this converging evidence suggests an early involvement of the enteric nervous system (ENS) in the pathogenesis of PD. Already over a decade ago, Braak and colleagues hypothesized that $\alpha$ Syn-immunoreactive inclusions first appear in the ENS and then occur in the parasympathetic (e.g., vagal output neurons in the intestines) and sympathetic (e.g., in the celiac ganglion in the upper abdomen) nervous system and gradually engage the brainstem, including the vagal dorsal motor nucleus and midbrain areas $[3,13]$. Several studies in preclinical models have demonstrated that $\alpha$ Syn pathology in the gut is associated with the development of $\alpha$ Syn pathology in the brain [14-20]. For a better understanding of PD pathogenesis and particularly events happening at preclinical stages of PD, it is critical to determine factors that regulate $\alpha$ Syn accumulation in the ENS 
and to understand whether the process underlying $\alpha$ Syn accumulation in the gut can also lead to $\alpha$ Syn pathology in the brain.

Inflammation can potentially trigger $\alpha$ Syn pathology in the ENS of the gut and in the brain. A recent finding in children with gastrointestinal inflammation suggests an immune regulatory function of $\alpha$ Syn [21]. Immune pathways are indeed activated in the brain and colon of PD cases [22,23]. Also, several genes associated with an increased PD risk have an immune system-related function [24], and it was recently proposed that PD heritability is not simply due to variation in brain-specific genes, but that several cell types in different tissues are involved [25]. Adding further genetic evidence supporting that inflammation is involved in PD pathogenesis, a genome-wide association study identified common genetic pathways linking PD and autoimmune disorders [26]. Most prominently, LRRK2, a major genetic risk factor for PD also confers increased risk for developing inflammatory bowel disease (IBD) [27] and is known to modulate the function of monocytes, macrophages and other immune cells $[28,29]$. Intriguingly, IBD is associated with an increased risk for developing PD and specifically blocking the tumor necrosis factor (TNF) pathway reduces this risk [30-34]. Recently, it was reported that experimental colitis in $\alpha$ Syn transgenic mice leads to enteric accumulation of $\alpha$ Syn and the development of PD-like brain pathology and symptoms within a few months [35]. Converging clinical and nonclinical data suggest that the intestinal immune environment plays a role in triggering PD or facilitating the molecular events involved in the earliest phases of the disease process $[36,37]$.

Here, we tested the hypothesis that specific types and severity of intestinal inflammation are required to trigger the accumulation of $\alpha$ Syn in the ENS and the subsequent development of $\alpha$ Syn pathology in

142 the brain. Experimental forms of colitis in wild type and $\alpha$ Syn transgenic mice demonstrated that the

143 type and degree of inflammation regulates the amount of $\alpha$ Syn accumulation in the colon. Macrophage-related signaling limited the extent of $\alpha$ Syn immunoreactivity. When $\alpha$ Syn transgenic mice were exposed to experimental colitis at 3 months of age and then were allowed to age normally up to 9 or 21 months, the accumulation of aggregated $\alpha \mathrm{Syn}$ in midbrain, including the $\mathrm{SN}$, was much exacerbated in the 21-month old group, but not in the 9-month old group. These 21-month old mice 
148 also exhibited loss of nigral tyrosine hydroxylase-immunoreactive neurons. Together, our data

149 provide evidence that certain specific forms of intestinal inflammation might be a relevant upstream

150 trigger that plays a critical role in the initiation of PD pathogenesis and the disease progression.

151

152 
154

155

156

157

\section{Aim, design and setting}

We aimed to combine an $\alpha$ Syn-transgenic mouse model of age-dependent development of $\alpha$ Syn pathology with well-established experimental colitis paradigms in order to explore the effect of type and severity of immune activation on the development of $\alpha$ Syn pathology in the colon and the brain. The design and setting of the different studies are illustrated in Fig. 1.

\section{Mice}

Male C57BL/6J wild type mice (Jackson Laboratories, Bar Harbor, USA), hemizygous Tg(Thy1SNCA*A30P)18Pjk ((Thy1)-h[A30P]aSyn ) [38] and Tg(Thy1-SNCA*A30P)18Pjk crossed with Cx3cr1tm1Litt ((Thy1)-h[A30P] Syn /Cx3cr1-def; homozygous for Cx3cr1-GFP knock-in allele; [39] transgenic mice were used for the study. (Thy1)-h[A30P] $\alpha$ Syn transgenic mice express mutant human $\alpha$ Syn under the neuron selective Thy1 promoter. (Thy1)-h[A30P] $\alpha$ Syn transgenic mice were crossed to $\mathrm{Cx} 3 \mathrm{cr} 1$-def transgenic mice which express eGFP replacing fractalkine receptor gene expression. All mice were maintained on a C57BL/6J background for more than 10 generations and under specific pathogen-free conditions. To the extent possible, littermates were used in the experiments. Health status was monitored daily during experiments. The in vivo experiments were endorsed by a Roche internal review board and approved by the local animal welfare authorities of the Canton Basel-Stadt, Basel, Switzerland.

\section{Experimental colitis paradigms in mice}

Paradigms for the induction of inflammation were either 1 week (acute) or 3-4 weeks (chronic) with or without an incubation phase under normal conditions of 2, 6, or 18 months post application (Fig. 1). Acute systemic inflammation was induced by intraperitoneal lipopolysaccharide (LPS) application [40] of $0.5 \mathrm{mg} / \mathrm{kg}$ in $100 \mu \mathrm{l}$ injection volume on day 1 and 4 (Sigma-Aldrich Chemie GmbH, Steinheim, Germany, LPS 055:B5). Acute colitis was induced by application of 36-50kDa Dextran Sulfate Sodium (DSS) [41] (160110, MP Biomedicals, LLC, Illkirch, France) at 0\%, 1\%, 2.5\% or 5\% 
in autoclaved drinking water for 5 continuous days respectively, followed by 2 days of water (1 DSS application cycle). Chronic colitis was achieved by 4 repeating DSS application cycles. The DSS concentration during 4 weeks of chronic colitis was either $1 \%$ or $2.5 \%$ for 4 weeks or $2.5 \%-4 \%$ raised $0.5 \%$ every week for 4 weeks. Mice from same littermate group were randomized per cage into vehicle and inflammation inducing agent.

\section{IL-10 treatment and exposure measurement}

Two different forms of mouse IgG bound murine IL-10 (mIgG(v1)-mIL10 and mIgG(v2)-mIL10) were diluted in pre-prepared sterile formulation buffer comprised of $0.5 \%$ mouse serum supplemented with $25 \mathrm{mM}$ citrate, $300 \mathrm{mM}$ arginine to a final concentration of $0.75 \mathrm{mg} / \mathrm{ml}$ and the $\mathrm{pH}$ adjusted to 6.7 on the day of application. Each mouse was treated once with $150 \mu \mathrm{g}$ i.p. concurrently with the initiation of the acute colitis paradigm with 5\% DSS. The concentrations of mIgG-mIL10 fusion proteins in murine serum samples were determined by enzyme-linked immunosorbent assays (ELISA) specific for the Fab moiety of the administered mIgG-mIL10 fusion protein. Biotinylated mIgGmIL10-specific target molecules were used for capturing, goat anti-mIg IgG-HRP conjugate and peroxidase substrate ABTS was used for quantitative detection of $\mathrm{mIgG}-\mathrm{mIL} 10$ fusion proteins.

\section{Immunohistochemistry}

Mice were injected with a lethal dose of pentobarbital (150 mg/kg). Upon full anesthesia, mice received transcardial perfusion with room temperature phosphate buffered saline (PBS). For biochemical and immunohistochemical analysis, one section of the proximal colon was either fresh frozen and stored at $-80^{\circ} \mathrm{C}$ or post-fixed in $4 \%$ paraformaldehyde (PFA) solution for $24 \mathrm{~h}$. Following post-fixation, organs were incubated in $30 \%$ sucrose/PBS at $4^{\circ} \mathrm{C}$ for at least $48 \mathrm{~h}$ before further processing. Subsequently, enteric tissue was cryotome-sectioned to $35 \mu \mathrm{m}$ thick longitudinal sections (approx. $1 \mathrm{~cm}$ length). The brain was collected and post-fixed for $24 \mathrm{~h}$ in $4 \%$ PFA followed by $30 \%$ sucrose in phosphate buffer until cryo-sectioning of floating sections at $40 \mu \mathrm{m}$. Histological analysis of mouse colon was performed using standard hematoxylin staining. Immunohistochemical staining was accomplished using the Vectastain Elite ABC Kits and Peroxidase Substrate Kit SK-4100 (Vector 
Laboratories, Burlingame, CA, USA) or fluorescently labelled secondary antibodies (Alexa coupled to dye 488, 555 or 647 , Life Technologies, Zug, Switzerland). The following primary antibodies have been used for overnight incubation at a dilution of 1:1000: monoclonal antibody to human $\alpha$-synuclein (clone 211, sc-12767, Santa Cruz Biotechnology, Heidelberg, Germany), monoclonal antibody generated towards rat $\alpha$-synuclein, cross-reactive with murine and human $\alpha \operatorname{Syn}$ (Syn1/clone 42, BD Transduction Laboratories, Allschwil, Switzerland; used for wild type mice), polyclonal antibody to the peripheral neuronal marker Peripherin (Millipore Corporation, Billerica, MA, USA), and polyclonal antibody to macrophage marker Iba1 (Wako Chemical GmbH, Neuss, Germany). To detect phosphorylated $\alpha$ Syn (pSer129 pathology) in the free-floating brain sections, monoclonal antibody (ab51253, Abcam, Cambridge, USA) to human $\alpha$ Syn was used at a dilution of 1:10000. Prior to the pSer129 staining, the free-floating brain sections were incubated for $10 \mathrm{~min}$ at room temperature in a phosphate buffered saline solution containing $10 \mu \mathrm{g} / \mathrm{mL}$ proteinase $\mathrm{K}$ (Cat \# 25530015; Invitrogen, California, USA). TH-immunoreactive cells were detected using a polyclonal antibody (657012, Millipore Sigma) at a dilution of 1:1000. To measure the density of Nissl-positive cells, the THstained cells were counter-stained with Cresyl violet. The slides were incubated in $0.1 \%$ Cresyl violet solution for 9 min and then dehydrated in $95 \%$ and $100 \%$ ethanol and then xylene prior to cover slipping with Cytoseal 60 mounting media (Thermo Fisher Scientific). Quantifications of the blindcoded TH/Nissl stained slides were done using Stereoinvestigator (version 2017.01.1; MBF Bioscience, Williams, VT, USA) on Imager M2 microscope (ZEISS) coupled to a computer. We analyzed 5-7 nigral sections per animal, and a total of 7-8 animals per treatment group. We outlined the substantia nigra pars compacta and counted every TH-immunoreactive and Nissl-positive cell in that area (using a counting frame of $40 \mu \mathrm{m} \times 40 \mu \mathrm{m}$, grid size of $140 \mu \mathrm{m} \times 140 \mu \mathrm{m}$, a guard zone of 2 $\mu \mathrm{m}$ and optical dissector height of $20 \mu \mathrm{m}$ ) and then computed the number of cells per section, generating the average cell count per animal. We then calculated the average count of cells per treatment group and analyzed the data using unpaired Student's T-test after confirming normality and homoscedasticity in Prism 7.0 (GraphPad Software). 
237 Imaging and stereological quantification was performed on a Zeiss Axio Imager Z2 fluorescence microscope (Carl Zeiss AG, Jena, Germany). Leica TCS SP5 confocal system using an HCX PL APO CS 40x 1.3 oil UV or an HCX PL APO LB 63x 1.4 oil UV objective was utilized for image recording. Accumulation of $\alpha$ Syn in the ENS was assessed on a random set of 3 adjacent $35 \mu \mathrm{m}$ thick, $\alpha$ Synimmunostained sections comprising the myenteric and submucosal neuronal plexuses. Analysis was performed with the aid of Stereologer software (Stereo Investigator 10, MBF Bioscience, Williams, VT, USA) as described previously [42]. In the myenteric plexus ganglion volume was defined by multiple outlined plexuses containing a range of 5-20 neuronal cells and quantified by the optical fraction fractionator technique. In contrast to the myenteric plexus, the submucosa consists of compact plexuses with 1-5 cells including interconnecting neurites. Therefore, the entire submucosa was set as region of interest, analyzed with the area fraction fractionator technique. Results of the submucosal plexus are displayed by percent area containing $\alpha$ Syn deposits. For the IL-10 experiment, $\alpha$ Syn positive inclusions from immunofluorescence images were counted for each image. Inclusion body-like features were filtered based on having a size between 12 and 50000 pixels and a minimal intensity value greater than 300 . The filtering step was included to exclude small background features and macrophages (very large spots). The counts were then aggregated to the animal level by summing the inclusion feature counts of all images per animal and then normalizing for (i.e. dividing by) the number of images for a given animal. Upon exploratory data analysis two animals were excluded: one mouse because it only had one image and another due it being an outlier, based on its infiltration score and image data.

\section{Quantification of leukocytes infiltration}

To determine the leukocyte covered area in the colon after LPS or DSS application, three adjacent hematoxylin stained sections were quantified. Total area of colon sections and localizations of leukocyte assemblies within the tissue architecture were identified and outlined utilizing Stereologer

262 Software (Stereo Investigator 6, MBF Bioscience, Williams, VT, USA). Percentage of leukocyte covered area has been set in proportion to total area of the analyzed colon section, e.g. to at least the 
length of $1 \mathrm{~cm}$ of proximal colon. For the IL-10 experiment, hematoxylin stained colon slices were examined by an expert pathologist blinded to treatment conditions. A score of $0-3$ was assigned to each section for each of the 3 layers lamina propria, submucosa and muscularis based on the degree of inflammatory infiltration. A score of 0 denoted no inflammation and a score of 3 indicated extensive infiltration. The mean of the values for all 3 layers was taken as the final measure of leukocyte infiltration per mouse.

\section{Quantification of aSyn/Ibal double positive macrophages}

The number of $\alpha$-syn-positive Iba1 cells was evaluated by quantification of 10 random regions in 2 adjacent sections of the proximal colon. The region of interest was set to contain the myenteric plexus/circular muscle layer and the submucosal plexus. Cells were assessed for positive $\alpha$ Syn staining and concomitant co-localization with the macrophage marker Iba1 was quantified.

\section{Scoring of pSer129 pathology and brain heatmap}

We evaluated pSer129 pathology on a full series of immunostained coronal sections from 10 mice per treatment group (i.e. water vs. DSS-treated groups) on blind-coded slides using a previously described method [43]. We visualized pathology from one hemisphere of all brain sections (apart from the olfactory area) using NIKON Eclipse Ni-U microscope and assigned scores ranging from 0 to 4 to each brain area based on the relative abundance of PK-resistant pSer129-positive inclusions (i.e. cell bodies and neurites). In this case, $0=$ no aggregates, $1=$ sparse, $2=$ mild, $3=$ dense, $4=$ very dense. For the heatmap, we obtained the average score values of each brain area for each treatment group. The average data for each treatment group ( $n=10$ / group) was then represented as a heatmap in a sagittal mouse brain background. To create the brain heatmap a postscript file downloaded freely from (http://atlas.brain-map.org/atlas?atlas=2\#atlas $=2 \&$ structure $=771 \&$ resolution $=16.75 \& x=$

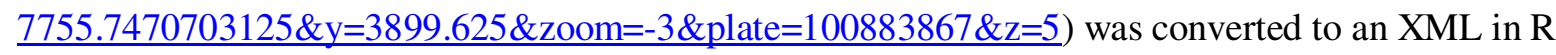
$\mathrm{v}$ 3.4.4, and the mean scores were manually assigned to respective brain regions. The remaining brain regions were estimated via the R package 'Akima', using a pointwise bivariate interpolation algorithm for irregular data on the mean $\mathrm{X}$ and $\mathrm{Y}$ coordinates for each brain region. 


\section{Densitometry of pSer129 aSyn brain pathology}

294 The density of pSer129 pathology in 12 major brain areas (reticular nucleus, pontine reticular nucleus, periaqueductal gray, gray and white layer, reticular formation, substantia nigra, ventral tegmental area, thalamus, hypothalamus, central amygdala, pallidum and striatum) was determined in the water and DSS-treated animals. A NIKON Eclipse Ni-U microscope was used to acquire 20x magnification images (without condenser lens) from all the indicated brain areas, using the same exposure time for all images. In all cases, images were acquired on three sections separated by $420 \mu \mathrm{m}$ intervals (localized between Bregma). We then processed the acquired images using Image J64 [44], created a mask (to exclude background) that redirects to the original image for analysis, measured the total area and the mean grey value of the area that had inclusions. For brain areas such as periaqueductal gray that do not fill the entirety of the field to be analyzed, we drew a contour of the area and the analysis was performed only within that contoured area. We subsequently calculated the grey value of the area per square pixels for each image (i.e. A.U./px ${ }^{2}=$ mean grey value $\mathrm{x}$ area stained/total area assessed). Based on this, we calculated the average grey value per square pixels for each brain area for each animal ( $\mathrm{n}=6$ mice/group), and then extended this calculation to determine the average grey value per square pixels for each treatment group and each of the twelve brain areas of interest.

\section{Blinding of experimenters for histological and immunohistochemical analyses}

For analyses of colon and brain tissue on slides, a second individual assigned unique codes to stained slides. Therefore, the experimenter conducted the analyses blinded to the identity of the mice. For randomization of treatment groups see above.

mRNA expression

316 To assess mRNA expression levels from the proximal colon, RNA was extracted from fresh frozen

317 tissue with MagnaLyser green beads (Roche Diagnostics, Mannheim, Germany) and Qiazol Lysis 
Hoffmann - La Roche AG, Rotkreuz, Switzerland) and amplified via real-time PCR (4ng RNA/reaction; Lightcycler 480, Roche Diagnostics Corporation, Indianapolis, USA). Amplification of mRNA was performed by using TaqMan probes for human or murine specific $\alpha$-synuclein and for selected cytokines/chemokines (Applied Biosystems Europe B.V., Zug, Switzerland). Target mRNA was normalized to tissue specific murine GAPDH levels and displayed as relative expression after 30 amplification cycles.

Statistics

Measurements for inflammation and $\alpha$ Syn accumulation in the ENS were taken from distinct samples (e.g. in three to six technical replicates per mouse). Data from each mouse was used only once, thus no repeated measure of same sample was performed. Statistical analysis of gut pathology and inflammation was performed using GraphPad Prism 6.04 or 7.0 software (GraphPad Software, Inc. La Jolla, CA, USA). The results are expressed as mean values \pm standard errors of the mean (SEM). Student's T-test (or Welch's T-test for unequal variances) was used to compare two groups and ANOVA was used for multi-comparison of groups followed by Tukey HSD post-hoc analysis. For the statistical analysis of the mRNA expression, data quality was assessed by inspecting the distribution of $\mathrm{Cp}$ values of reference endogenous genes across samples, by inspecting the level of $\mathrm{Cp}$ variation between technical replicates and by exploring the samples multivariate signal distribution as in a principal component analysis. Relative gene expression levels were expressed as $2^{\text {-(Cpgene-CpRef). }}$ Statistical analyses to assess the effect of the experimental conditions on the $\log 2$ gene expression levels were done with linear models using the limma package (Bioconductor/R, [45]). These analyses were implemented in $\mathrm{R}$ v3.1.1.

For the statistical modelling of the effects of the IL-10 treatment on $\alpha$ Syn counts, as well as infiltration scores, the levels for IgG1(v1)-IL10 and IgG1(v2)-IL10 treatment were compared to the positive (vehicle/DSS) control. Additionally, since levels of the control antibody treatment (IgG1(v1)) were very similar to the positive control, the two groups were pooled in further contrasts in which effects of individual antibodies or control IgG was assessed. For $\alpha$ Syn counts in the enteric nervous system, a linear model on the treatment groups with one-degree freedom contrasts was applied. For 
347 the infiltration score a Kruskal-Wallis test, with the same contrasts, was used. All statistical tests were 348 two-tailed with a significance level of $\mathrm{p}<0.05$.

349 For the statistical analysis of the pSer129 $\alpha$ Syn brain pathology, zero-inflated negative-binomial 350 mixed-effects models with a random intercept for each sample and variance assumed to increase 351 linearly with the mean (verified against a quadratic increase using Akaike Information Criterion [AIC] 352 and Bayesian Information Criterion [BIC]) were used to analyze the dataset via the 'glmmTMB' 353 package in $\mathrm{R} v$ 3.4.4. Linear contrasts with false discovery rate (FDR) adjustments were then used to 354 test our hypotheses and account for multiple testing (for brain area and experimental group). 

mice

During the process of further characterizing a (Thy1)-h[A30P] Syn transgenic mouse line [38], we detected human $\alpha$ Syn accumulation in all innervated organs that were analyzed (Additional File 1

Suppl. Fig. 1). This included the myenteric and submucosal plexuses of the ENS, where human $\alpha$ Syn co-localized with peripherin, a specific marker for peripheral nerves (Fig. 1a). We observed an agedependent increase of baseline human $\alpha$ Syn inclusions (irregularly sized and shaped inclusion bodies detected by human $\alpha$ Syn specific monoclonal antibody clone 211) in both plexuses between the ages of three and twelve months (Fig. 1b). We wanted to test whether IBD-related experimental inflammation in the colon exacerbates this local accumulation of $\alpha$ Syn acutely (e.g. within a few days or weeks) and how the age of the $\alpha$ Syn transgenic mice influenced the outcome. Administration of dextran sulfate sodium (DSS) in the drinking water in acute or chronic paradigms are well-established mouse models of experimental colitis mimicking aspects of IBD, i.e. by exhibiting infiltration of leukocytes into the submucosa with various degrees of destruction of the colonic mucosa and submucosa [46]. It is well known, that the DSS model can vary substantially based on the genetic background of the mice and due to different animal housing environments. Thus, in order to establish the DSS model in our environment and with our mice, we first tested DSS administration at different concentrations and durations in the (Thy1)-h[A30P] $\alpha$ Syn transgenic mice (Fig. 1c), and observed leukocyte infiltration in a dose-dependent manner, which was similar at the age of 3 and 6 months (Fig. 1d and 2a). In the acute paradigm with mice at the age of 3 months, $2.5 \%$, but not $1 \%$, DSS triggered intracellular accumulation of $\alpha$ Syn in nerves of the submucosal plexus (Fig. 2a, b). In the chronic DSS paradigm, which was initiated in the mice at the age of 3 months (and terminated when they were 6 months old; these animals were allowed to age to 6 months following the one month chronic treatment; Fig. 1c and 2c), we observed a dose-dependent increase of $\alpha$ Syn load in the submucosal plexus, but at a smaller magnitude than in the younger mouse cohort (Fig. 2a). In that context, it was also interesting to observe that (Thy1)-h[A30P] $\alpha$ Syn transgenic mice exposed to acute 
DSS colitis presented with several $\alpha$ Syn-positive cells with a morphology consistent with them being

384 infiltrating leucocytes, which we confirmed to be positive for the macrophage marker Iba-1 (Suppl.

Fig. 2). This finding was relevant for the quantification of $\alpha$ Syn inclusions in the myenteric and submucosal plexus; i.e. such features were excluded from the quantification process.

Wild type mice also express endogenous $\alpha$ Syn in innervated organs, but at much lower levels compared with human $\alpha$ Syn protein that was overexpressed by the hemizygous (Thy1)-h[A30P] $\alpha$ Syn transgenic mice (Suppl. Fig. 1). To confirm that the finding in (Thy1)-h[A30P] 2 Syn transgenic mice was independent of transgenic expression of human $\alpha$ Syn, we applied the acute and the constant dose chronic DSS paradigms also in wild type mice (Fig. 1c). In both treatment paradigms, we observed in the submucosal plexus small inclusion bodies of endogenous murine $\alpha$ Syn (detected by rodent crossreactive $\alpha$ Syn-specific monoclonal antibody Syn1/clone 42, Fig. 2c, d). These features were close to undetectable in the water group that did not experience experimental colitis. A separate experiment also confirmed that the observed effects of DSS could not be attributed to increased gene expression of murine or the transgenic human $\alpha$ Syn (Suppl. Fig. 3). Together, these results confirmed the validity of this experimental IBD paradigm to test the effect of inflammation on $\alpha$ Syn accumulation in the ENS in wild type and (Thy1)-h[A30P] $\alpha$ Syn transgenic mice. Because 3-month old (Thy1)$\mathrm{h}[\mathrm{A} 30 \mathrm{P}] \alpha$ Syn transgenic mice provided more optimal conditions for visualization and quantification of $\alpha$ Syn inclusions in the ENS, for the remainder of the study we focused on using this transgenic mouse model.

\section{Colitis induced by peroral DSS but not by peritoneal administration of LPS aggravates aSyn}

\section{accumulation in colonic submucosal plexus of aSyn transgenic mice}

In order to explore the effects of different approaches to induce inflammation in or nearby the gut in (Thy1)-h[A30P] $\alpha$ Syn transgenic mice, we compared the outcome of acute 5\% DSS in drinking water with acute $0.5 \mathrm{mg} / \mathrm{kg}$ intraperitoneal LPS administration (Fig. 1c and 3). To maximize the inflammatory response, we administered both DSS and LPS at relatively high doses. At day 7, both agents had induced variable degrees of leukocyte infiltration in the submucosa of the colon while a marked destruction of the mucosa was induced when giving only DSS (Fig. 1d). As before, the DSS- 
exposed mice presented with increased accumulation of $\alpha$ Syn in the ganglia of the submucosal plexus

412 (Fig. 3a). In contrast, we detected no change in $\alpha$ Syn load in the myenteric plexus, consistent with

413 lack of leukocyte infiltration in this part of the colonic wall (Fig. 3b). Despite the high dose, LPS-

414 induced inflammation did not increase $\alpha$ Syn accumulation in the colonic nervous plexuses (Fig. 3c,

415 d). Notably, LPS and DSS resulted in a differential expression of cytokines, and consistent with

416 leukocyte recruitment, CCL2 was elevated in both (Fig. 3f, g). In the LPS paradigm, mRNA for IL-10

417 was markedly elevated, whereas DSS strongly increased IL-6 and also IL-1 $\beta$ but not IL-10. Together

418 these results indicate that, in our model, colonic inflammation induced by peroral DSS but not

419 intraperitoneal LPS increases the accumulation of $\alpha$ Syn in the colon.

Lack of Cx3cr1 signaling during DSS colitis aggravates aSyn load in the submucosal plexus of

\section{aSyn transgenic mice}

423 Given the role of monocytes/macrophages in IBD and in the related DSS paradigm, we hypothesized further that modulating monocytes/macrophages may affect accumulation of $\alpha$ Syn in our DSS model as well. In a first set of experiments we manipulated monocytes/macrophages genetically by crossing (Thy1)-h[A30P] $\alpha$ Syn transgenic mice with mice that have a deletion for the fractalkine receptor Cx3cr1 (Cx3cr1-GFP knock-in mice) (Fig. 3a, b). The CX3CR1-CX3CL1 axis plays an important role in maintaining the function of the lamina propria macrophage population of the gastrointestinal wall and lack of this signaling pathway in experimental colitis models may either aggravate or ameliorate the induced pathology [47-49]. In our experiment, the area covered by infiltrating leukocytes following exposure to DSS was near the mucosa and submucosa and was not significantly higher in the Cx3cr1-deficient $\alpha$ Syn transgenic mice than in the Cx3cr1-competent mice (Suppl. Fig. 3a). However, a significantly higher level of $\alpha$ Syn accumulated in the submucosal plexus in $\alpha$ Syn transgenic mice lacking Cx3cr1 compared to $\alpha$ Syn transgenic mice expressing $\mathrm{Cx} 3 \mathrm{cr} 1(\mathrm{p}=0.001$, two-way ANOVA with Tukey HSD post-hoc analysis; Fig. 3a). In the myenteric plexus, we found no marked increase in $\alpha$ Syn accumulation in neither the $\alpha$ Syn transgenic mice with normal Cx $3 \mathrm{cr} 1$ nor the $\alpha$ Syn transgenic mice deficient in $\mathrm{Cx} 3 \mathrm{crl}$, indicating as in the experiments above a possible prominent role for the localization of leukocyte infiltration in the process of $\alpha$ Syn accumulation in the 
submucosa (Fig. 3b). Collectively, our results in Cx3cr1-deficent $\alpha$ Syn transgenic mice provide a potential association between monocyte/macrophage signaling and $\alpha$ Syn accumulation in ENS in this experimental IBD model.

Systemic IL-10 ameliorates DSS-induced colitis and associated enteric aSyn accumulation in aSyn

To continue testing the hypothesis that modulating monocytes/macrophages may affect accumulation of $\alpha$ Syn in our DSS model we moved to a pharmacological modulation of this cellular subset. Interleukin-10 (IL-10) is an important regulator of monocytes/macrophages, and genetic ablation of IL-10 signaling or blocking IL-10 with specific antibodies has been reported to enhance DSS colitis [50,51]. In the experiments with LPS we had also noted an increase of IL-10 compared with the DSS paradigm and LPS inflammation was in contrast to DSS colitis not associated with increased $\alpha$ Syn accumulation in the ENS (Fig. 3). To mimic the effect of higher levels of IL-10 in an acute model of DSS colitis (5\% DSS, Fig. 1c), we administered intravenously recombinant murine IL-10 (mIL10). The half-life of injected recombinant IL-10 protein in blood is very short. To reduce the number of injections, we extended the half-life of mIL-10 in circulation by engineering it onto two different murine $\mathrm{IgG}$ variants (i.e., $\mathrm{mIgG1}(\mathrm{v} 1)-\mathrm{mIL} 10$ and $\mathrm{mIgG1}(\mathrm{v} 2)-\mathrm{mIL} 10$, respectively). As described above, DSS induced a marked increase in leukocyte infiltration and $\alpha$ Syn accumulation, and we found both to be similar in the untreated and control IgG treated group (Fig. 4a, b). In contrast, both mIgG1(v1)-mIL10 and mIgG1(v2)-mIL10 significantly reduced leukocyte infiltration in mice treated with DSS ( $\mathrm{p}<0.0001$, one-way ANOVA with Tukey HSD post-hoc analysis; Fig. 4a, b). A significant down-regulatory effect of an IL-10 treatment on DSS colitis induced accumulation of human $\alpha$ Syn in the submucosal plexus was only observed with mIgG1(v2)-mIL10 (p=0.02, one-way ANOVA with Tukey HSD post-hoc analysis; Fig. 4b). This effect by mIgG1(v2)-mIL10 on $\alpha$ Syn levels was accompanied by detectable serum levels of mIgG1(v2)-mIL10 at the end of the in vivo phase, whereas mIgG1(v1)-mIL10 was no longer detectable at that point (Fig. 4c). This indicates that although both forms of IL-10 have a down-regulatory effect on leukocyte infiltration, a sustained pharmacological exposure of IL-10 may be required for reducing $\alpha$ Syn accumulation. These results highlight an 
important role for the IL-10 pathway in keeping $\alpha$ Syn accumulation at a reduced level throughout the course of experimental IBD. Together, our observations by genetic (i.e. CX3CR1-CX3CL1 axis) and pharmacological modulation (i.e. IL-10) of DSS colitis corroborate an important role for monocyte/macrophage pathways in the development of $\alpha$ Syn accumulation in the ENS of the colon.

471

DSS colitis-induced submucosal aSyn accumulation at a young age persists for months and is exacerbated by lack of Cx3cr1 signaling

In humans there is strong epidemiological evidence that IBD increases PD risk [30,32,34] and recent evidence in Crohn's disease [52] indicate that such gut inflammatory conditions are associated with $\alpha$ Syn accumulation in the ENS [33]. In mice we have until here established and replicated in different setups a link between modulation of inflammation and induction of $\alpha$ Syn accumulation in the ENS. Because longer exposure to DSS mimics more closely the chronic nature of IBD, we elected to explore $\alpha$ Syn accumulation in the submucosal plexus of (Thy1)-h[A30P] $\alpha$ Syn transgenic mice that were subjected to DSS colitis in a 4-week chronic increasing dose paradigm. In order to allow for a full recovery from the chronic inflammation, we aged the mice for two months on normal drinking water and analyzed them at the age of 6 months (Fig. 1c). At this point we wanted again to explore the effect of modulating monocytes/macrophages in this chronic setting and added an experimental arm with (Thy1)-h[A30P] $]$ Syn transgenic mice lacking Cx3cr1. As expected, after 2 months of recovery, the area that is usually extensively covered by leukocytes in the submucosal plexus of the acute DSS paradigm had returned to normal levels following the two-month recovery period (Suppl.

Fig. 4a). Remarkably, however, $\alpha$ Syn accumulation in the ganglia of the submucosal plexus was still almost doubled when compared to $\alpha$ Syn transgenic mice that were not exposed to DSS, and this was exacerbated in $\alpha$ Syn transgenic mice deficient for Cx3cr1 (Suppl. Fig. 4b). The finding in the $\alpha$ Syn transgenic mice suggests that accumulation of $\alpha \mathrm{Syn}$ is not a transient effect or response. In addition, modulation of monocytes/macrophages by down-regulating the CX3CR1-CX3CL1 axis contributes to aggravation of this accumulation. 
At this point, we have established and repeatedly demonstrated that modulation of inflammatory mechanisms in experimental colitis induced by acute and chronic DSS administration is causatively linked to induction and persistence of $\alpha$ Syn accumulation in the ENS of young adult mice. The previously highlighted hypothesis by Braak and colleagues associates $\alpha$ Syn brain pathology in PD with $\alpha$ Syn pathology in the ENS earlier in life $[3,53]$. To assess development of brain $\alpha$ Syn pathology and to link it again to IBD risk, we exposed 3-month old hemizygous (Thy1)-h[A30P] $\alpha$ Syn transgenic mice to DSS or normal drinking water and after 23 days on this chronic increasing dose paradigm returned all mice to normal drinking water until sacrifice (Fig. 1c, increasing dose). We chose to use the $\alpha$ Syn transgenic model rather than wild type mice for this study because of two reasons: 1) we knew that the model as hemizygous transgenic mice exhibit some $\alpha$ Syn brain pathology that develops slowly under baseline conditions. Importantly, the pathology is much less pronounced than in homozygous (Thy1)-h[A30P] $\alpha$ Syn mice [54]; 2) at the time of the experiment, it was not clear whether wild type mice could develop $\alpha$ Syn brain pathology upon DSS colitis. Thus, we chose hemizygous (Thy1)-h[A30P] $\alpha$ Syn transgenic mice to increase the chances for a successful outcome and potentially to aggravate the brain pathology from mild to strong. After exposing the mice either to normal drinking water or a chronic DSS paradigm, we aged them in two cohorts on normal water and housing conditions to either up to the age of 9 months (cohort 1) or 21 months (cohort 2). At these two timepoints we analyzed various brain regions for pathological $\alpha$ Syn (proteinase K resistant, pSer129- $\alpha$ Syn immunoreactive inclusions). When we examined the $\alpha$ Syn transgenic mice of cohort 1 , we found that both experimental groups (i.e. those who were on DSS and those who stayed on normal water throughout their entire life and thus never experienced DSS colitis) exhibited extremely low levels of pathological $\alpha$ Syn inclusions in the brain (Fig. 5A-F, M-Q and Suppl. Fig. 5a). Our observation of the level of pathological $\alpha$ Syn inclusions in the brain of these 9-month old hemizygous (Thy1)-h[A30P] $\alpha$ Syn transgenic mice is indeed consistent with earlier descriptions of the model at the age of 11 months [54]. Similarly for cohort 2, the 21-month old hemizygous (Thy1)-h[A30P] Syn transgenic mice that only received water during their lifetimes showed relatively low levels of 
pathological $\alpha$ Syn in the brain (Fig. 5G-I and Suppl. Fig. 5b), which is consistent with previous

523

524

525

526

527

528

529

530

531

532

533

534

535

536

537

538

539

540

541

542

543

544

545

546

547

548

observations in this transgenic line at the age of 24 months [54]. In marked contrast, the 21 -month-old hemizygous (Thy1)-h[A30P] SSyn transgenic mice that were exposed to DSS at three months of age presented with pSer129-positive $\alpha$ Syn pathology throughout various brain regions in a much more exacerbated fashion than mice that were aged up to 21 months without having experienced DSS colitis at young age (Fig. 5J-L, R-V and Suppl. Fig. 5c). The degree and distribution of proteinase $\mathrm{K}$ resistant $\alpha$ Syn was similar to what was previously described for homozygous (Thy1)-h[A30P] $\mathrm{S}$ Syn transgenic mice at the age of 8 to 9 months [54]. The significant aggravation of $\alpha$ Syn pathology in the substantia nigra $(\mathrm{p} \leq 0.01$ in a negative-binomial mixed-effects model adjusting for multiple comparisons performed over all brain areas) was accompanied by a significant loss of tyrosine hydroxylase (TH) and Nissl-positive cells at 21 months of age ( $\mathrm{p} \leq 0.05$, Student's T-test; Fig. 6). Together, we found that experimental DSS colitis at a young age caused an age-dependent exacerbation of $\alpha$ Syn inclusion pathology and a loss of nigral dopaminergic neurons in the brains of (Thy1)-h[A30P] Syn transgenic mice.

6

7

\section{Discussion}

Currently, there is no therapy for PD available to slow or stop disease progression and an obstacle in the quest to develop one is that we do not understand how the disease develops [55]. Intraneuronal accumulation of $\alpha$ Syn (i.e. in Lewy bodies and neurites) is a key neuropathological hallmark and the distribution of Lewy pathology in postmortem brain is used for staging in PD $[2,56]$. Accumulation of $\alpha$ Syn has also been observed in the peripheral nervous system in PD, some individuals at risk of developing the disease, and normal individuals [57-59]. Similar to this finding in people, $\alpha$ Synimmunoreactive inclusions have also been detected in the ENS of a transgenic mouse model prior to changes in the brain [60]. Based on preclinical models employing injection of recombinant $\alpha$ Syn fibrils to different brain regions and intestines $[15,16,19,20,43,61,62]$ together with postmortem brain pathology $[53,56,63]$, it has also been suggested that $\alpha$ Syn pathology propagates temporospatially 
from cell-to-cell in a prion-like manner $[3,56,61,63,64]$. However, the initial factors triggering $\alpha$ Syn aggregation are yet to be established [55] and the involvement of peripheral stimuli in the aggregation and pathogenic spread of $\alpha$ Syn is only beginning to unravel.

In this study, we provide evidence that DSS colitis, i.e. an experimental IBD-like inflammation, triggers $\alpha$ Syn accumulation in the ENS of wild type mice and in a transgenic mouse model of PD

(Fig. 2). We found aggravation of enteric $\alpha$ Syn accumulation in $\alpha$ Syn transgenic mice lacking Cx3cr1 signaling and amelioration of inflammation and enteric $\alpha$ Syn load by systemic IL-10, demonstrating that genetic and pharmacologic modulation of inflammation can influence the degree of $\alpha$ Syn accumulation in the ENS (Fig. 3 and 4). The capability of IL-10 and the CX3CR1-CX3CL1 axis being able to mediate this effect suggests that monocytes/macrophages modulate the process in this model. We further observed that the aggravated $\alpha$ Syn accumulation in the ENS persisted even after two months of recovery from DSS colitis and was aggravated in the absence of CX3CR1 signaling. This indicates that the effect is not transient and further establishes that monocytes/macrophages play a critical role in this process (Suppl. Fig. 4). Remarkably, at 18 months but not 6 months post induction of DSS colitis (thus, at age 21 months but not 9 months, respectively), $\alpha$ Syn transgenic mice had developed massively elevated $\alpha$ Syn brain pathology (Fig. 5 and Suppl. Fig. 5). This elevated proteinase K resistant pSer129- $\alpha$ Syn pathology in the midbrain, including the substantia nigra, and other brain regions coincided with an average decrease of 30-50\% of TH- and Nissl-positive cells in the nigra (Fig. 6). We chose to perform the long-term experiments in $\alpha$ Syn transgenic mice rather than wild type mice. These particular $\alpha$ Syn transgenic mice had previously been shown to slowly develop $\alpha$ Syn pathology in the brain on a homozygous genotype $[38,54]$ making them ideal when asking the question of whether transient colonic inflammation can aggravate brain pathology in a genetically predisposed animal such as the hemizygous transgenic mice used in this study. Others have recently

572 demonstrated in a more aggressive $\alpha$ Syn transgenic mouse model that mild DSS colitis can accelerate $573 \alpha$ Syn accumulation in the ENS and brain [35]. In future long-term studies, we plan to address whether 574 aSyn pathology develops also in the brains of wild type mice if they sustain transient experimental IBD at a young age. In our experiments presented here, experimental DSS colitis in $\alpha$ Syn transgenic 
mice recapitulated the accumulation of enteric $\alpha$ Syn which is proposed to occur in humans several years before PD diagnosis [36]. Additionally, the subsequent age-related development of $\alpha$ Syn pathology in the brain of $\alpha$ Syn transgenic mice together with the loss of nigral dopaminergic neurons mimicked a progression of the disease similar to what is considered to occur in PD.

We established that a mechanism by which a specific type of peripheral inflammation promotes $\alpha$ Syn accumulation in the colon potentially involves monocytes and macrophages. Both peroral DSS and intraperitoneal LPS administration provoked strong local immune reactions resulting in leukocyte infiltration into the submucosa of the colon. The region of the colon which was inflamed contains the submucosal plexus and is anatomically separated from the myenteric plexus by a thick circular muscle (Fig. 1). This discrete localization of inflammation to the submucosa might explain why $\alpha$ Syn only accumulated in the nerves of the submucosal plexus and not in the myenteric plexus of our mice that received DSS in both a strong acute and the two chronic paradigms. The mechanism underlying how intraperitoneally administered LPS leads to submucosal leukocyte infiltration likely involves the monocyte attractant chemokine CCL2 (Fig. 3), but the specifics remain to be clarified [65]. Indeed, CCL2 was also upregulated in the colon of our DSS model. However, in contrast to intraperitoneal LPS, where infiltrating macrophages were present in discrete patches in the colonic wall, DSS-related macrophage infiltration was distributed both in small groups and larger randomly distributed patches of cells across the entire colonic submucosa. Also, perorally administered DSS destroys the mucosa of the colon, similar to some forms of ulcerative colitis, resulting in the transient disintegration of the intestinal epithelial barrier. In our (Thy1)-h[A30P] $\alpha$ Syn transgenic mice, the subsequent immune response to the infiltration of commensal bacteria evoked an elevated expression of cytokines such as IL-1 $\beta$ and IL-6, a phenomenon also observed in in the colon of IBD patients $[66,67]$. This upregulation was absent in the LPS paradigm in which the intestinal mucosa remained intact. By acting on tight junctions, IL-1 $\beta$ and IL-6 can increase intestinal barrier permeability (gut leakiness), facilitating the recruitment of additional immune cells to the site of the inflammation, eventually culminating in widespread immune activation $[68,69]$. Consistent with the breach of barrier permeability in our mouse model, some PD patients exhibit increased colonic cytokines such as IL- 
$1 \beta$, IL-6 and TNF, occurring together with increased intestinal permeability [22,70]. In this context, it is also notable that people with Crohn's disease present with increased enteric $\alpha$ Syn expression [52] and even more striking that IBD patients on anti-TNF therapy have a reduced risk of developing PD compared to IBD patients not given this treatment [32]. Notably, mucosal macrophages with intralysosomal $\alpha$ Syn content were previously described in the intact human appendix [71]. These macrophages were in close proximity to the axonal varicosities of the vermiform appendix, which showed an enriched staining for $\alpha$ Syn in the mucosal plexus. Furthermore, we recently found that the vermiform appendix contains aggregated and truncated $\alpha$ Syn that has the propensity to seed aggregation of recombinant $\alpha$ Syn in vitro [59].

612 What could be a functional role of the $\alpha$ Syn species found in abundance in the gut wall? Monomeric and oligomeric $\alpha$ Syn species reportedly act as chemoattractants for neutrophils and monocytes, enhancing the maturation of dendritic cells in the ENS $[21,72]$. With such a role in intestinal immunity, it is possible that the tissue destruction induced by DSS in the present study led to release of $\alpha$ Syn, which perhaps served as a chemoattractant for monocytes. The increased abundance of $\alpha$ Syn and altered intestinal permeability, along with the DSS-evoked inflammatory response may have provided an enabling milieu allowing further $\alpha$ Syn accumulation in the ENS of the colon [73]. Macrophages and other immune cells are also regulated by several genes including $L R R K 2$, an established risk gene for PD and IBD. It will be interesting to explore how mutations in genes that control autophagy, including the $L R R K 2$ gene, influence the handling of $\alpha$ Syn by macrophages that invade the inflamed colon in our DSS colitis paradigm. Despite the intriguing translational aspect of our finding in the DSS paradigm, others have very recently reported that DSS colitis in mice downregulates the expression of enteric $\alpha$ Syn on protein levels in vivo $[74,75]$. This is in contrast to our immunofluorescence (i.e. increased accumulation of $\alpha$ Syn in submucosal plexus upon DSS colitis;

Fig. 2, 3, 4 and 5) and gene expression data (e.g., no change in endogenous and transgenic $\alpha$ Syn upon DSS colitis; Suppl. Fig. 3) in the same paradigm and may reflect the well-known lab-to-lab variability that can occur for the DSS models [76]. 
629 Perhaps the most striking finding in our study was that a single period of DSS-induced colitis at a

630 young age led to an exacerbation of $\alpha$ Syn pathology in the brain of $\alpha$ Syn transgenic mice much later

631 in life (Fig. 6). How does severe $\alpha$ Syn inclusion pathology develop in the brains of these mice? One

632 hypothesis is that the brain $\alpha$ Syn pathology observed in this study could be due to direct effects of

633 peripheral immune activation on the brain and that certain peripheral triggers can directly affect

634 microglial activity. For instance, short-chain fatty acids derived from gut microbiota appear to

635 influence function and maturation of microglia in the mouse brain [77] and inflammatory mediators

636 released by gut microbiota into the bloodstream have been suggested to induce brain pathology and

637 behavioral changes in an $\alpha$ Syn transgenic mouse model [78]. Moreover, rats and nematodes have been

638 reported to develop $\alpha$ Syn inclusions after exposure to the bacterial amyloid protein curli, a protein

639 which stimulates microgliosis, astrogliosis, and secretion of IL-6 and TNF [79]. Intriguingly, a recent

640 study reported that peripherally applied inflammatory stimuli induce acute immune training (that

641 exacerbates $\beta$-amyloid pathology) and immune tolerance in the brain that reprograms microglia, an

642 effect which can persist for at least six months [80]. Whether this is a relevant mechanism in the DSS

643 paradigm needs to be explored.

644 Another hypothesis is that the observed brain $\alpha$ Syn pathology may have accumulated as a

645 consequence of the transfer of pathogenic $\alpha$ Syn seeds from the gut via the vagal nerve. Several

646 experimental studies have demonstrated that pathogenic $\alpha$ Syn seeds can be transferred from the

647 peripheral to the central nervous system. Aggregated recombinant $\alpha$ Syn injected intraperitoneally,

648 intramuscularly or into the gastric wall of certain mouse models of PD results in $\alpha$ Syn inclusions in

649 the brain [16,81]. Data from animals injected with recombinant $\alpha$ Syn protein in the gut wall or viral

650 vectors expressing $\alpha$ Syn into the vagal nerve suggest that pathogenic seeds can be transmitted via the

651 vagal nerve $[15,19,20,62,82-84]$. A role for the vagal nerve in PD was also suggested by an

652 epidemiological study indicating that vagotomy in a Danish population is associated with decreased

653 PD risk [85], although this association has been challenged [86]. In the present study, $\alpha$ Syn pathology

654 was much more prominent in the reticular nucleus (including the vagal nucleus) and midbrain areas

655 compared to the rostral areas at 18 months post DSS colitis. Although we did not conduct the 
definitive experiment of cutting the vagal nerve, our data are consistent with the growing body of evidence that the vagal nerve is involved in the accumulation of $\alpha$ Syn aggregates in the brain. That said, the innervation of the colon occurs via both parasympathetic (e.g., vagal output neurons) and sympathetic (e.g., in the celiac ganglion of the upper abdomen) nerves. The possibility of propagation of $\alpha$ Syn pathology via the two routes is supported by the observation that injection of recombinant $\alpha$ Syn fibrils to the duodenum of certain $\alpha$ Syn transgenic rats leads to accumulation of pathological $\alpha$ Syn in organs innervated by the parasympathetic and the sympathetic nerves [62] and that $\alpha$ Syn accumulation present in both peripheral nervous structures in humans as well [87]. Thus, propagation may occur through both vagal and spinal routes.

\section{Conclusion}

We report that $\alpha$ Syn accumulates in the colon of $\alpha$ Syn transgenic and wildtype mice subjected to experimental DSS colitis and that this process can be modulated by modifying genetically and pharmacologically pathways related to monocyte/macrophage signaling. We further demonstrate that chronic but transient DSS colitis in young $\alpha$ Syn transgenic mice leads to a markedly exacerbated accumulation of $\alpha$ Syn aggregates in the brain when the mice age. In the same aged mice, the numbers of TH- and Nissl-positive neurons in the substantia nigra are reduced, suggestive of a neurodegenerative process. Together, our findings are in consonance with studies demonstrating a link between IBD and PD $[30,32,88]$ and suggest a critical role for specific types of intestinal inflammation and $\alpha$ Syn accumulation in the initiation and progression of PD.

\section{List of abbreviations}

CCL2: Chemokine (C-C motif) ligand 2; CD: Crohn's disease; CX3CR1: CX3C Chemokine receptor 1 (fractalkine receptor); DSS: Dextran Sulfate Sodium; ELISA: Enzyme-linked immunosorbent assays; ENS: Enteric nervous system; FDR: False discovery rate; IBD: Inflammatory bowel disorder; 
681

682

683

684

685

686

687

688

689

690

691

692

693

694

695

696

697

698

699

700

701

702

703

704

705

706

707

IL: Interleukin; LPS: Lipopolysaccharide; PBS: Phosphate buffered saline; PD: Parkinson's disease; PFA: Paraformaldehyde; PK: Proteinase K; pSer129: $\alpha$-synuclein phosphorylated at serine 129; SEM: Standard error of the mean; SN: Substantia nigra; TH: Tyrosine hydroxylase; TNF: Tumor necrosis factor; UC: Ulcerative colitis; $\alpha$ Syn: $\alpha$-Synuclein.

5

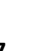

\section{Declarations}

\section{Ethics approval and consent to participate}

The in vivo experiments were endorsed by a Roche internal review board and approved by the local animal welfare authorities of the Canton Basel-Stadt, Basel, Switzerland.

\section{Consent for publication}

Not applicable

\section{Availability of data and materials}

The datasets used and/or analyzed in this study are available from the corresponding author on reasonable request.

\section{Competing interest}

At the time of the study S.G. and N.M. were Roche Postdoctoral Fellows employed by Roche and L.S., F.B., G.D.P., J.S.P., K.O.S., H.R., M.H., M.Se. M.St., P.M., A.W., T.E., A.H. and M.B. are or were fulltime employees or trainees at Roche and they may additionally hold Roche stock/stock options. S.G. and L.S. are currently employees of Neurimmune AG, Schlieren, Switzerland. P.B. has received commercial support as a consultant from Renovo Neural, Inc., AbbVie, Neuroderm, Fujifilm-Cellular Dynamics International, Axial Biotherapeutics, and IOS Press Partners. He has received commercial support for grants/research from Lundbeck A/S, Renovo, and Roche. He has 
ownership interests in Acousort $\mathrm{AB}$ and Axial Biotherapeutics and is on the steering committee of the NILO-PD trial. The other authors declare that they have no competing interest with regard to this research.

\section{Funding}

P.B. reports grants from the National Institutes of Health (1R01DC016519-01, 5R21NS093993-02, 1R21NS106078-01A1) and Office of the Assistant Secretary of Defense for Health Affairs (Parkinson's Research Program, Award No. W81XWH-17-1-0534). S.G and N.M. were supported by a grant from Roche under the Roche Postdoctoral Fellowship (RPF) Program.

\section{Authors' contributions}

S.G., N.M. and L.S. planned and performed the in vivo experiments, colon immunostaining, analysis, and quantification; S.G. and N.M. drafted a first version of the manuscript; E.Q. performed, imaged, quantitated pSer129, TH and Nissl staining in the brain sections, and drafted a more advanced version of the manuscript with J.A.S., who also provided helpful discussion. F.B. and K.O.S. supported the image acquisition and image analysis for the colon samples; M.St. performed imaging and data analysis of experiments with wildtype mice; G.D.P. and J.S.P. performed statistical analysis of the DSS experiments; H.R. and M.H. performed mRNA analyses; M.Se. trained S.G. and L.S. on mouse necropsy and supported their work; P.M. performed expert pathology staging on leukocyte infiltration; T.E. and A.W. provided mIgG-mIL-10 fusion proteins and measured serum exposure; Z.M. performed statistical analysis for the pSer129 aSyn immunohistochemistry data. A.S. contributed with scientific and veterinary expert input for implementation and analysis of the DSS colitis model at Roche. M.L.E.G. provided helpful discussion and project planning. A.H. co-mentored S.G. and N.M., performed expert pathology staging on leukocyte infiltration and contributed to experimental planning. C.M. trained S.G. on the colitis model and provided expert input on the experimental IBD model. M.B. and P.B. co-mentored Roche Postdoctoral Fellows S.G. and N.M., conceived and oversaw the study, and performed experimental planning; M.B., P.B. and E.Q. wrote the final version of the manuscript. All authors read and approved the final manuscript. 


\section{Acknowledgments}

738 We thank Drs. L. Ozmen and A. Bergadano for their tremendous support in maintaining the mouse 739 colony and we are grateful to the animal caretakers, veterinarians and many unnamed staff at Roche 740 for their valuable work with the mice in this study. In addition, at Roche we thank Dr. K.G. Lassen for 741 critical input to the paper, Dr. C. Ullmer for co-mentoring S.G. and providing scientific input, Dr. L.

742 Collin for helping with confocal imaging and we are grateful to Dr. T. Kremer, N. Haenggi, D. Mona,

743 A. Girardeau, and J. Messer for providing support in tissue dissections and G. Walker and R. Lauria 744 for technical support. Ms. E. Schulz from VARI assisted with immunostaining of the brain tissue. We 745 thank the Contract Research Organization Frimorfo for carefully sectioning the brains for this study.

746 We acknowledge Drs. L. Gaudimier (née Chicha) and F. Pan-Montojo for scientific discussions early

747 in the project, Dr. W. Zago from Prothena for valuable scientific input throughout the project, and

748 Drs. M. and P. Derkinderen for critical input on the link between IBD and the enteric $\alpha$ Syn 749 accumulation in humans. 
751 1. Tysnes O-B, Storstein A. Epidemiology of Parkinson's disease. J Neural Transm (Vienna).

$752 \quad 2017 ; 124: 901-5$.

753 2. Spillantini MG, Goedert M. Neurodegeneration and the ordered assembly of $\alpha$-synuclein. Cell

754 Tissue Res. 2017;373:137-48.

755

756

757

758

759

760

761

762

763

764

765

766

767

768

769

770

771

772

773

774

775

776

777

778

779

780

781

782

783

3. Del Tredici K, Braak H. Lewy pathology and neurodegeneration in premotor Parkinson's disease. Mov Disord. 2012;27:597-607.

4. Polymeropoulos MH, Lavedan C, Leroy E, Ide SE, Dehejia A, Dutra A, et al. Mutation in the alpha-synuclein gene identified in families with Parkinson's disease. Science. 1997;276:2045-7.

5. Schrag A, Horsfall L, Walters K, Noyce A, Petersen I. Prediagnostic presentations of Parkinson's disease in primary care: a case-control study. Lancet Neurol. 2015;14:57-64.

6. Gaenslen A, Swid I, Liepelt-Scarfone I, Godau J, Berg D. The patients' perception of prodromal symptoms before the initial diagnosis of Parkinson's disease. Mov Disord. 2011;26:653-8.

7. Pont-Sunyer C, Hotter A, Gaig C, Seppi K, Compta Y, Katzenschlager R, et al. The onset of nonmotor symptoms in Parkinson's disease (the ONSET PD study). Mov Disord. 2015;30:229-37.

8. Berg D, Godau J, Seppi K, Behnke S, Liepelt-Scarfone I, Lerche S, et al. The PRIPS study: screening battery for subjects at risk for Parkinson's disease. Eur J Neurol. 2013;20:102-8.

9. Postuma RB, Gagnon J-F, Bertrand J-A, Génier Marchand D, Montplaisir JY. Parkinson risk in idiopathic REM sleep behavior disorder: preparing for neuroprotective trials. Neurology. 2015;84:1104-13.

10. Abbott RD, Petrovitch H, White LR, Masaki KH, Tanner CM, Curb JD, et al. Frequency of bowel movements and the future risk of Parkinson's disease. Neurology. 2001;57:456-62.

11. Savica R, Carlin JM, Grossardt BR, Bower JH, Ahlskog JE, Maraganore DM, et al. Medical records documentation of constipation preceding Parkinson disease: A case-control study. Neurology. 2009;73:1752-8.

12. Mahlknecht P, Seppi K, Poewe W. The Concept of Prodromal Parkinson's Disease. J Parkinsons Dis. 5:681-97.

13. Braak H, de Vos RAI, Bohl J, Del Tredici K. Gastric alpha-synuclein immunoreactive inclusions in Meissner's and Auerbach's plexuses in cases staged for Parkinson's disease-related brain pathology. Neurosci Lett. 2006;396:67-72.

14. Phillips RJ, Walter GC, Wilder SL, Baronowsky EA, Powley TL. Alpha-synucleinimmunopositive myenteric neurons and vagal preganglionic terminals: autonomic pathway implicated in Parkinson's disease? Neuroscience. 2008;153:733-50.

15. Holmqvist S, Chutna O, Bousset L, Aldrin-Kirk P, Li W, Björklund T, et al. Direct evidence of Parkinson pathology spread from the gastrointestinal tract to the brain in rats. Acta Neuropathol. 2014;128:805-20.

16. Breid S, Bernis ME, Babila JT, Garza MC, Wille H, Tamgüney G. Neuroinvasion of $\alpha$-Synuclein Prionoids after Intraperitoneal and Intraglossal Inoculation. J Virol. 2016;90:9182-93. 
17. Sargent D, Verchère J, Lazizzera C, Gaillard D, Lakhdar L, Streichenberger N, et al. "Prion-like" propagation of the synucleinopathy of M83 transgenic mice depends on the mouse genotype and type of inoculum. J Neurochem. 2017;143:126-35.

18. Manfredsson FP, Luk KC, Benskey MJ, Gezer A, Garcia J, Kuhn NC, et al. Induction of alphasynuclein pathology in the enteric nervous system of the rat and non-human primate results in gastrointestinal dysmotility and transient CNS pathology. Neurobiol Dis. 2018;112:106-18.

19. Arotcarena M-L, Dovero S, Prigent A, Bourdenx M, Camus S, Porras G, et al. Bidirectional gutto-brain and brain-to-gut propagation of synucleinopathy in non-human primates. Brain. Oxford Academic; 2020;143:1462-75.

20. Challis C, Hori A, Sampson TR, Yoo BB, Challis RC, Hamilton AM, et al. Gut-seeded $\alpha$ synuclein fibrils promote gut dysfunction and brain pathology specifically in aged mice. Nature Neuroscience. Nature Publishing Group; 2020;23:327-36.

21. Stolzenberg E, Berry D, Yang D, Lee EY, Kroemer A, Kaufman S, et al. A Role for Neuronal Alpha-Synuclein in Gastrointestinal Immunity. JIN. 2017;9:456-63.

22. Devos D, Lebouvier T, Lardeux B, Biraud M, Rouaud T, Pouclet H, et al. Colonic inflammation in Parkinson's disease. Neurobiol Dis. 2013;50:42-8.

23. Mogi M, Harada M, Kondo T, Riederer P, Inagaki H, Minami M, et al. Interleukin-1 beta, interleukin-6, epidermal growth factor and transforming growth factor-alpha are elevated in the brain from parkinsonian patients. Neurosci Lett. 1994;180:147-50.

24. Brás J, Guerreiro R, Hardy J. SnapShot: Genetics of Parkinson’s disease. Cell. 2015;160:570570.e1.

25. Reynolds RH, Botía J, Nalls MA, Hardy J, Taliun SAG, Ryten M. Moving beyond neurons: the role of cell type-specific gene regulation in Parkinson's disease heritability. npj Parkinson's Disease. 2019;5:6.

26. Witoelar A, Jansen IE, Wang Y, Desikan RS, Gibbs JR, Blauwendraat C, et al. Genome-wide Pleiotropy Between Parkinson Disease and Autoimmune Diseases. JAMA Neurol. 2017;74:780-92.

27. Umeno J, Asano K, Matsushita T, Matsumoto T, Kiyohara Y, Iida M, et al. Meta-analysis of published studies identified eight additional common susceptibility loci for Crohn's disease and ulcerative colitis. Inflamm Bowel Dis. 2011;17:2407-15.

28. Gardet A, Benita Y, Li C, Sands BE, Ballester I, Stevens C, et al. LRRK2 is involved in the IFNgamma response and host response to pathogens. J Immunol. 2010;185:5577-85.

29. Hakimi M, Selvanantham T, Swinton E, Padmore RF, Tong Y, Kabbach G, et al. Parkinson's disease-linked LRRK2 is expressed in circulating and tissue immune cells and upregulated following recognition of microbial structures. J Neural Transm (Vienna). 2011;118:795-808.

30. Lin J-C, Lin C-S, Hsu C-W, Lin C-L, Kao C-H. Association Between Parkinson's Disease and Inflammatory Bowel Disease: a Nationwide Taiwanese Retrospective Cohort Study. Inflamm Bowel Dis. 2016;22:1049-55.

31. Nerius M, Doblhammer G, Tamgüney G. GI infections are associated with an increased risk of Parkinson's disease. Gut. 2019;gutjnl-2019-318822. 
32. Peter I, Dubinsky M, Bressman S, Park A, Lu C, Chen N, et al. Anti-Tumor Necrosis Factor Therapy and Incidence of Parkinson Disease Among Patients With Inflammatory Bowel Disease. JAMA Neurol. 2018;75:939-46.

33. Rolli-Derkinderen M, Leclair-Visonneau L, Bourreille A, Coron E, Neunlist M, Derkinderen P. Is Parkinson's disease a chronic low-grade inflammatory bowel disease? J Neurol. 2019;1-7.

34. Wan Q-Y, Zhao R, Wu X-T. Older patients with IBD might have higher risk of Parkinson's disease. Gut. 2018; gutjnl-2018-317103.

35. Kishimoto Y, Zhu W, Hosoda W, Sen JM, Mattson MP. Chronic Mild Gut Inflammation Accelerates Brain Neuropathology and Motor Dysfunction in $\alpha$-Synuclein Mutant Mice.

Neuromolecular Med. 2019;

36. Houser MC, Tansey MG. The gut-brain axis: is intestinal inflammation a silent driver of Parkinson's disease pathogenesis? npj Parkinson’s Disease. 2017;3:3.

37. Joers V, Masilamoni G, Kempf D, Weiss AR, Rotterman TM, Murray B, et al. Microglia, inflammation and gut microbiota responses in a progressive monkey model of Parkinson's disease: A case series. Neurobiology of Disease. 2020;144:105027.

38. Kahle PJ, Neumann M, Ozmen L, Muller V, Jacobsen H, Schindzielorz A, et al. Subcellular localization of wild-type and Parkinson's disease-associated mutant alpha -synuclein in human and transgenic mouse brain. J Neurosci. 2000;20:6365-73.

39. Jung S, Aliberti J, Graemmel P, Sunshine MJ, Kreutzberg GW, Sher A, et al. Analysis of fractalkine receptor $\mathrm{CX}(3) \mathrm{CR} 1$ function by targeted deletion and green fluorescent protein reporter gene insertion. Mol Cell Biol. 2000;20:4106-14.

40. Kitazawa M, Oddo S, Yamasaki TR, Green KN, LaFerla FM. Lipopolysaccharide-induced inflammation exacerbates tau pathology by a cyclin-dependent kinase 5-mediated pathway in a transgenic model of Alzheimer's disease. J Neurosci. 2005;25:8843-53.

41. Schenk M, Bouchon A, Seibold F, Mueller C. TREM-1--expressing intestinal macrophages crucially amplify chronic inflammation in experimental colitis and inflammatory bowel diseases. $\mathbf{J}$ Clin Invest. 2007;117:3097-106.

42. Grathwohl SA, Kälin RE, Bolmont T, Prokop S, Winkelmann G, Kaeser SA, et al. Formation and maintenance of Alzheimer's disease $\beta$-amyloid plaques in the absence of microglia. Nat Neurosci. 2009;12:1361-3.

43. Rey NL, George S, Steiner JA, Madaj Z, Luk KC, Trojanowski JQ, et al. Spread of aggregates after olfactory bulb injection of $\alpha$-synuclein fibrils is associated with early neuronal loss and is reduced long term. Acta Neuropathol. 2017;1-19.

44. Schneider CA, Rasband WS, Eliceiri KW. NIH Image to ImageJ: 25 years of image analysis. Nat Methods. 2012;9:671-5.

45. Smyth GK. limma: Linear Models for Microarray Data. In: Gentleman R, Carey VJ, Huber W, Irizarry RA, Dudoit S, editors. Bioinformatics and Computational Biology Solutions Using R and Bioconductor [Internet]. New York, NY: Springer New York; 2005 [cited 2019 May 1]. p. $397-420$. Available from: https://doi.org/10.1007/0-387-29362-0_23

46. Chassaing B, Aitken JD, Malleshappa M, Vijay-Kumar M. Dextran sulfate sodium (DSS)-induced colitis in mice. Curr Protoc Immunol. 2014;104:Unit 15.25. 
47. Weber B, Saurer L, Schenk M, Dickgreber N, Mueller C. CX3CR1 defines functionally distinct intestinal mononuclear phagocyte subsets which maintain their respective functions during homeostatic and inflammatory conditions. Eur J Immunol. 2011;41:773-9.

48. Medina-Contreras O, Geem D, Laur O, Williams IR, Lira SA, Nusrat A, et al. CX3CR1 regulates intestinal macrophage homeostasis, bacterial translocation, and colitogenic Th17 responses in mice. J Clin Invest. 2011;121:4787-95.

49. Kostadinova FI, Baba T, Ishida Y, Kondo T, Popivanova BK, Mukaida N. Crucial involvement of the CX3CR1-CX3CL1 axis in dextran sulfate sodium-mediated acute colitis in mice. J Leukoc Biol. 2010;88:133-43.

50. Kang S, Okuno T, Takegahara N, Takamatsu H, Nojima S, Kimura T, et al. Intestinal epithelial cell-derived semaphorin 7A negatively regulates development of colitis via $\alpha \mathrm{v} \beta 1$ integrin. J Immunol. 2012;188:1108-16.

51. Li B, Alli R, Vogel P, Geiger TL. IL-10 modulates DSS-induced colitis through a macrophageROS-NO axis. Mucosal Immunol. 2014;7:869-78.

52. Prigent A, Lionnet A, Durieu E, Chapelet G, Bourreille A, Neunlist M, et al. Enteric alphasynuclein expression is increased in Crohn's disease. Acta Neuropathol. 2019;137:359-61.

53. Braak H, Del Tredici K, Rüb U, de Vos RAI, Jansen Steur ENH, Braak E. Staging of brain pathology related to sporadic Parkinson's disease. Neurobiol Aging. 2003;24:197-211.

54. Neumann M, Kahle PJ, Giasson BI, Ozmen L, Borroni E, Spooren W, et al. Misfolded proteinase K-resistant hyperphosphorylated alpha-synuclein in aged transgenic mice with locomotor deterioration and in human alpha-synucleinopathies. J Clin Invest. 2002;110:1429-39.

55. Johnson ME, Stecher B, Labrie V, Brundin L, Brundin P. Triggers, Facilitators, and Aggravators: Redefining Parkinson's Disease Pathogenesis. Trends Neurosci. 2018;S0166-2236:30253-4.

56. Braak H, Del Tredici K, Bratzke H, Hamm-Clement J, Sandmann-Keil D, Rüb U. Staging of the intracerebral inclusion body pathology associated with idiopathic Parkinson's disease (preclinical and clinical stages). J Neurol. 2002;249 Suppl 3:III/1-5.

57. Shannon KM, Keshavarzian A, Dodiya HB, Jakate S, Kordower JH. Is alpha-synuclein in the colon a biomarker for premotor Parkinson's disease? Evidence from 3 cases. Mov Disord. 2012;27:716-9.

58. Lebouvier T, Neunlist M, Bruley des Varannes S, Coron E, Drouard A, N'Guyen J-M, et al. Colonic biopsies to assess the neuropathology of Parkinson's disease and its relationship with symptoms. PLoS ONE. 2010;5:e12728.

59. Killinger BA, Madaj Z, Sikora JW, Rey N, Haas AJ, Vepa Y, et al. The vermiform appendix impacts the risk of developing Parkinson's disease. Sci Transl Med. 2018;10:eaar5280.

60. Kuo Y-M, Li Z, Jiao Y, Gaborit N, Pani AK, Orrison BM, et al. Extensive enteric nervous system abnormalities in mice transgenic for artificial chromosomes containing Parkinson disease-associated $\alpha$-synuclein gene mutations precede central nervous system changes. Hum Mol Genet. 2010;19:163350.

61. Luk KC, Kehm V, Carroll J, Zhang B, O’Brien P, Trojanowski JQ, et al. Pathological $\alpha$-synuclein transmission initiates Parkinson-like neurodegeneration in nontransgenic mice. Science.

2012;338:949-53. 
62. Van Den Berge N, Ferreira N, Gram H, Mikkelsen TW, Alstrup AKO, Casadei N, et al. Evidence for bidirectional and trans-synaptic parasympathetic and sympathetic propagation of alpha-synuclein in rats. Acta Neuropathol. 2019;

63. Spillantini MG, Schmidt ML, Lee VM, Trojanowski JQ, Jakes R, Goedert M. Alpha-synuclein in Lewy bodies. Nature. 1997;388:839-40.

64. Rey NL, Steiner JA, Maroof N, Luk KC, Madaj Z, Trojanowski JQ, et al. Widespread transneuronal propagation of $\alpha$-synucleinopathy triggered in olfactory bulb mimics prodromal Parkinson's disease. J Exp Med. 2016;213:1759-78.

65. Puntambekar SS, Davis DS, Hawel L, Crane J, Byus CV, Carson MJ. LPS-induced CCL2 expression and macrophage influx into the murine central nervous system is polyamine-dependent. Brain Behav Immun. 2011;25:629-39.

66. Andus T, Daig R, Vogl D, Aschenbrenner E, Lock G, Hollerbach S, et al. Imbalance of the interleukin 1 system in colonic mucosa-association with intestinal inflammation and interleukin 1 receptor agonist genotype 2. Gut. 1997;41:651-7.

67. Sanchez-Muñoz F, Dominguez-Lopez A, Yamamoto-Furusho JK. Role of cytokines in inflammatory bowel disease. World J Gastroenterol. 2008;14:4280-8.

68. Al-Sadi RM, Ma TY. IL-1beta causes an increase in intestinal epithelial tight junction permeability. J Immunol. 2007;178:4641-9.

69. Capaldo CT, Nusrat A. Cytokine regulation of tight junctions. Biochim Biophys Acta. 2009;1788:864-71.

70. Forsyth CB, Shannon KM, Kordower JH, Voigt RM, Shaikh M, Jaglin JA, et al. Increased Intestinal Permeability Correlates with Sigmoid Mucosa alpha-Synuclein Staining and Endotoxin Exposure Markers in Early Parkinson's Disease. PLOS ONE. 2011;6:e28032.

71. Gray MT, Munoz DG, Gray DA, Schlossmacher MG, Woulfe JM. Alpha-synuclein in the appendiceal mucosa of neurologically intact subjects. Mov Disord. 2014;29:991-8.

72. Labrie V, Brundin P. Alpha-Synuclein to the Rescue: Immune Cell Recruitment by AlphaSynuclein during Gastrointestinal Infection. JIN. 2017;9:437-40.

73. Kelly LP, Carvey PM, Keshavarzian A, Shannon KM, Shaikh M, Bakay RAE, et al. Progression of Intestinal Permeability Changes and Alpha-Synuclein Expression in a Mouse Model of Parkinson's Disease. Mov Disord. 2014;29:999-1009.

74. Prigent A, Gonzales J, Durand T, Le Berre-Scoul C, Rolli-Derkinderen M, Neunlist M, et al. Acute inflammation down-regulates alpha-synuclein expression in enteric neurons. J Neurochem. 2019;148:746-60.

75. Resnikoff H, Metzger JM, Lopez M, Bondarenko V, Mejia A, Simmons HA, et al. Colonic inflammation affects myenteric alpha-synuclein in nonhuman primates. J Inflamm Res. 2019;12:11326.

76. Whittem CG, Williams AD, Williams CS. Murine Colitis Modeling using Dextran Sulfate Sodium (DSS). J Vis Exp [Internet]. 2010 [cited 2019 Apr 27]; Available from:

https://www.ncbi.nlm.nih.gov/pmc/articles/PMC2841571/ 
77. Erny D, Hrabě de Angelis AL, Jaitin D, Wieghofer P, Staszewski O, David E, et al. Host microbiota constantly control maturation and function of microglia in the CNS. Nat Neurosci. 2015;18:965-77.

78. Sampson TR, Debelius JW, Thron T, Janssen S, Shastri GG, Ilhan ZE, et al. Gut Microbiota Regulate Motor Deficits and Neuroinflammation in a Model of Parkinson's Disease. Cell. 2016;167:1469-1480.e12.

79. Chen SG, Stribinskis V, Rane MJ, Demuth DR, Gozal E, Roberts AM, et al. Exposure to the Functional Bacterial Amyloid Protein Curli Enhances Alpha-Synuclein Aggregation in Aged Fischer 344 Rats and Caenorhabditis elegans. Scientific Reports. 2016;6:34477.

80. Wendeln A-C, Degenhardt K, Kaurani L, Gertig M, Ulas T, Jain G, et al. Innate immune memory in the brain shapes neurological disease hallmarks. Nature. 2018;556:332-8.

81. Sacino AN, Brooks M, Thomas MA, McKinney AB, Lee S, Regenhardt RW, et al. Intramuscular injection of $\alpha$-synuclein induces CNS $\alpha$-synuclein pathology and a rapid-onset motor phenotype in transgenic mice. Proc Natl Acad Sci U S A. 2014;111:10732-7.

82. Kim S, Kwon S-H, Kam T-I, Panicker N, Karuppagounder SS, Lee S, et al. Transneuronal Propagation of Pathologic $\alpha$-Synuclein from the Gut to the Brain Models Parkinson's Disease. Neuron [Internet]. 2019 [cited 2019 Jul 25];0. Available from: https://www.cell.com/neuron/abstract/S08966273(19)30488-X

83. Lohmann S, Bernis ME, Tachu BJ, Ziemski A, Grigoletto J, Tamgüney G. Oral and intravenous transmission of $\alpha$-synuclein fibrils to mice. Acta Neuropathol. 2019;

84. Uemura N, Yagi H, Uemura MT, Hatanaka Y, Yamakado H, Takahashi R. Inoculation of $\alpha$ synuclein preformed fibrils into the mouse gastrointestinal tract induces Lewy body-like aggregates in the brainstem via the vagus nerve. Molecular Neurodegeneration. 2018;13:21.

85. Svensson E, Horváth-Puhó E, Thomsen RW, Djurhuus JC, Pedersen L, Borghammer P, et al. Vagotomy and subsequent risk of Parkinson's disease. Ann Neurol. 2015;78:522-9.

86. Tysnes O-B, Kenborg L, Herlofson K, Steding-Jessen M, Horn A, Olsen JH, et al. Does vagotomy reduce the risk of Parkinson's disease? Ann Neurol. 2015;78:1011-2.

87. Braak H, Sastre M, Bohl JRE, de Vos RAI, Del Tredici K. Parkinson's disease: lesions in dorsal horn layer I, involvement of parasympathetic and sympathetic pre- and postganglionic neurons. Acta Neuropathol. 2007;113:421-9.

88. Villumsen M, Aznar S, Pakkenberg B, Jess T, Brudek T. Inflammatory bowel disease increases the risk of Parkinson's disease: a Danish nationwide cohort study 1977-2014. Gut. 2018;68:18-24. 
Grathwohl et al., Figure 1
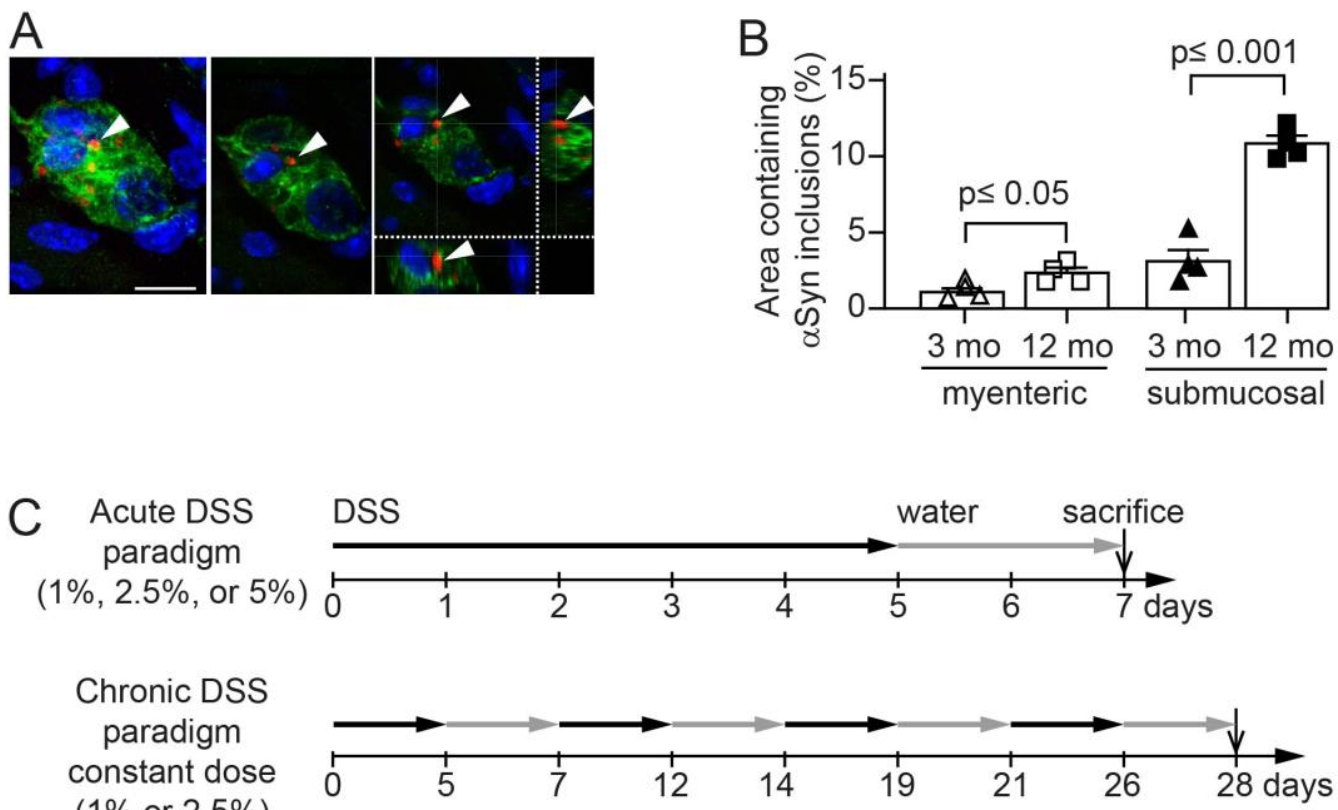

( $1 \%$ or $2.5 \%)$
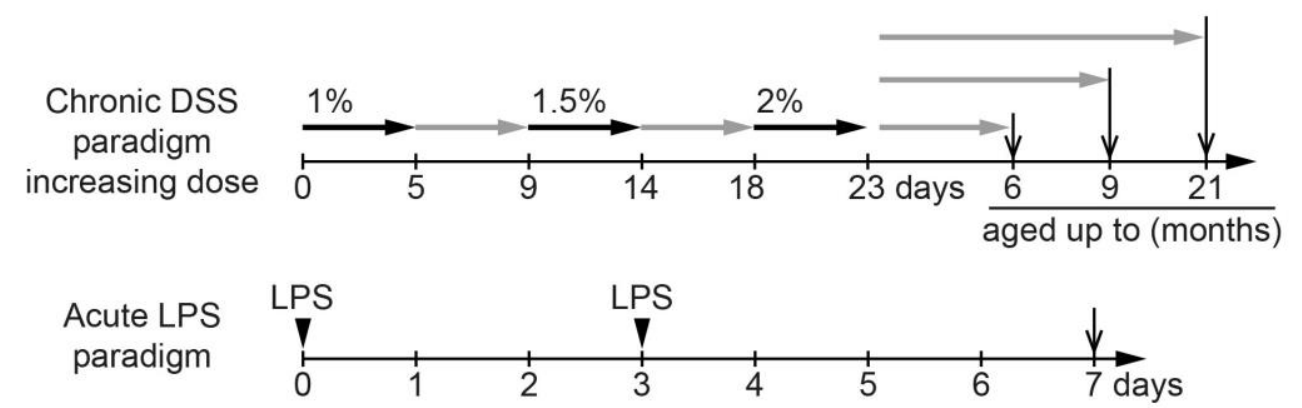

D

Intact colon

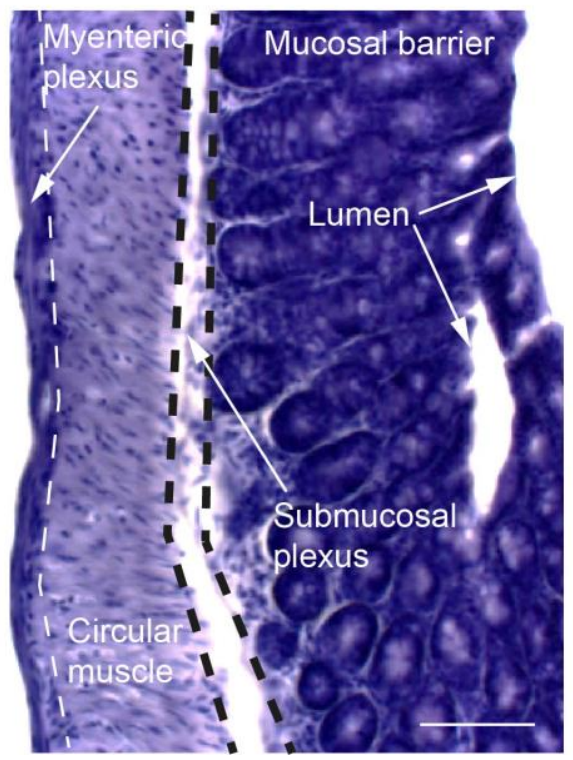

Acute DSS

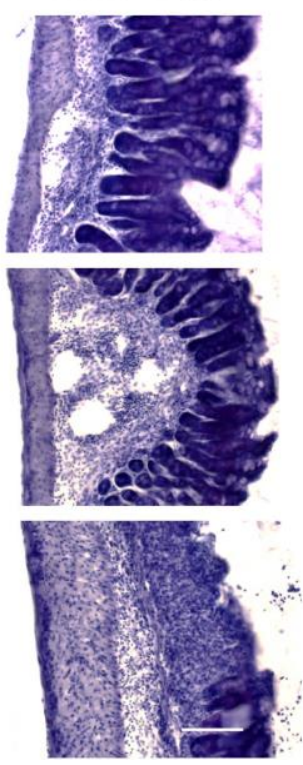

Acute LPS
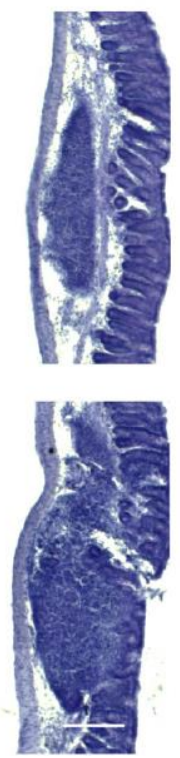
Fig. 1 Age dependent increase of intracellular $\alpha$ Syn accumulation in enteric nervous system of hemizygous (Thy1)-h[A30P]aSyn transgenic mice and setup of the experimental colitis paradigms. a Confocal microscopy imaging of the inclusions of human $\alpha$ Syn (red, antibody clone 211; human $\alpha$ Syn specific) within the ganglia of the submucosal plexus (green, peripherin; blue, DAPI/nuclei) of hemizygous (Thy1)-h[A30P] 2 Syn transgenic mice. Arrowhead points to one of the typical irregularly sized and shaped $\alpha$ Syn inclusion bodies visualized in $2 \mathrm{D}$ z-stacks of rotated confocal images. Scale bar, $100 \mu \mathrm{m}$. b Stereological quantification of normally occurring human $\alpha$ Syn inclusions in the myenteric and submucosal plexuses of 3 and 12 months old hemizygous (Thy1)$\mathrm{h}[\mathrm{A} 30 \mathrm{P}] \alpha$ Syn transgenic mice $(\mathrm{n}=4$ per group; mean and S.E.M. are shown; Student $\mathrm{t}$-test between the two age groups in each region). c Setup of experimental colitis paradigms employing dextran sulfate sodium (DSS, per os in drinking water). Additionally, peripheral inflammation was induced by bacterial lipopolysaccharide (LPS, intraperitoneal injection). After some chronic DSS paradigms mice were aged on normal water up to 6,9 or 21 months. Mice aged up to 9 or 21 months of age were analyzed for brain pathology $\mathbf{d}$ Hematoxylin staining of $35 \mu \mathrm{m}$ thick colon sections of 3 months old hemizygous (Thy1)-h[A30P] $\alpha$ Syn transgenic mice. Organizational layers of the intact colon (left panel). Representative images of various severity degrees of DSS-driven colitis from weak leukocyte infiltration (top panel of acute DSS) to more extensive leukocyte infiltration with mucosal ulceration (lowest panel of acute DSS). Note the different appearance of enteric inflammation in acute LPSdriven peripheral inflammation compared with DSS; e.g., confined immune cell clustering and lymphoid hyperplasia; intact mucosal layer. Scale bar $50 \mu \mathrm{m}$ (intact colon), $100 \mu \mathrm{m}$ (acute DSS), and $200 \mu \mathrm{m}$ (LPS). 
A
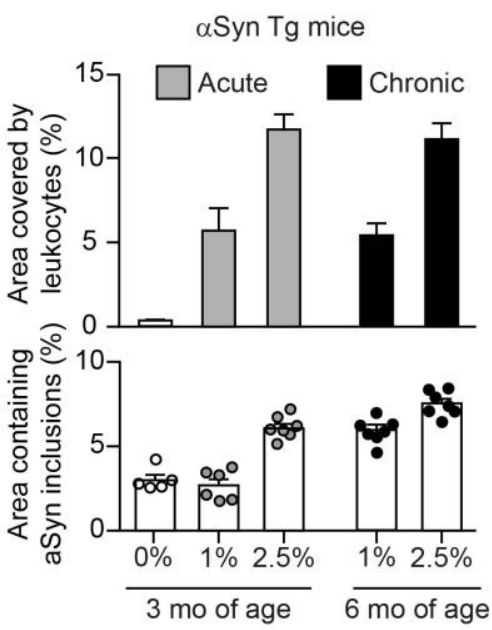

C

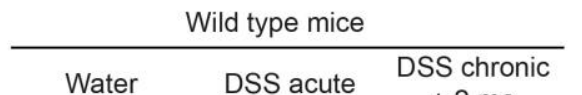

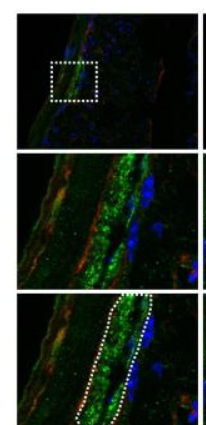

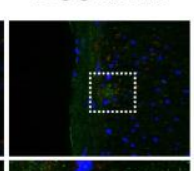
$+2 \mathrm{mo}$
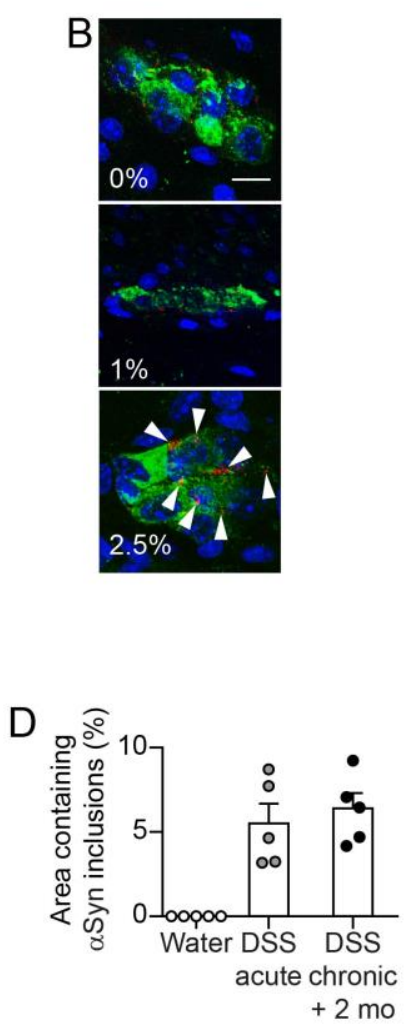

\section{Fig. 2 Colitis severity and duration-dependent aggravation of accumulation of $\alpha$ Syn inclusions} in the colonic submucosal plexus of hemizygous (Thy1)-h[A30P] $\alpha$ Syn transgenic and wild type mice. a DSS dose-dependent increase of leukocyte infiltration in the acute and chronic paradigm. The highest acute dose $(2.5 \%)$ and the two constant chronic doses led to an increase of $\alpha$ Syn inclusions in the submucosal plexus (stereological quantification of $\alpha$ Syn inclusions in the submucosal plexus of 3 and 6 months old hemizygous (Thy1)-h[A30P] Syn transgenic mice; $n=5-7$ per group; mean and s.e.m. are shown). $\mathbf{b}$ Representative $2 \mathrm{D}$ z-stacks of confocal images of increasing abundance of $\alpha$ Syn inclusions (red, human- $\alpha$ Syn specific monoclonal antibody clone 211) in a ganglion of the submucosal plexus (green, peripherin) with cellular nuclei in blue (DAPI) in the acute DSS paradigm. Arrow heads point to the typical irregularly sized and shaped $\alpha$ Syn inclusion bodies that accumulate 
in the highest DSS dose. Scale bar $200 \mu \mathrm{m}$. c Overview of colonic region of 3-month-old wildtype

1018 mice (top row) exposed to water or acute DSS (5\%) with immunofluorescence analysis of murine

$1019 \alpha$ Syn load in the colon performed immediately after colitis or exposed to constant chronic DSS (2.5\%)

1020 and analysis after aging on normal water for another 2 months. White dotted rectangles in the top row

1021 indicate the area that was zoomed out below illustrating in more detail the murine $\alpha$ Syn inclusions

1022 (red, rodent $\alpha$ Syn cross-reactive monoclonal antibody syn1/clone 42 ) in the submucosal plexus

1023 (green, peripherin). The lower three rows show DAPI and $\alpha$ Syn inclusions with and without the

1024 peripherin channel. The white dotted circled area illustrates the peripherin-positive area that was

1025 analyzed for $\alpha$ Syn inclusion bodies (arrow heads in bottom row). Scale bar for the lower three panels

$1026200 \mu \mathrm{m}$. d Stereological quantification of murine $\alpha$ Syn inclusions in the submucosal plexus of

1027 wildtype mice right after acute DSS colitis or after 2 months of recovery from a 4-week chronic DSS

1028 colitis ( $n=5$ per group). Note the regularly arranged and smoothly distributed immunoreactivity for the physiological $\alpha$ Syn with barely any inclusion bodies in the intact enteric nerves of the water group. Statistical analysis for $\alpha$ Syn accumulation was omitted as the noticeable differences between the means are self-evident (error bars indicate standard error of the mean) and an indication for an estimation for significance would be futile. 

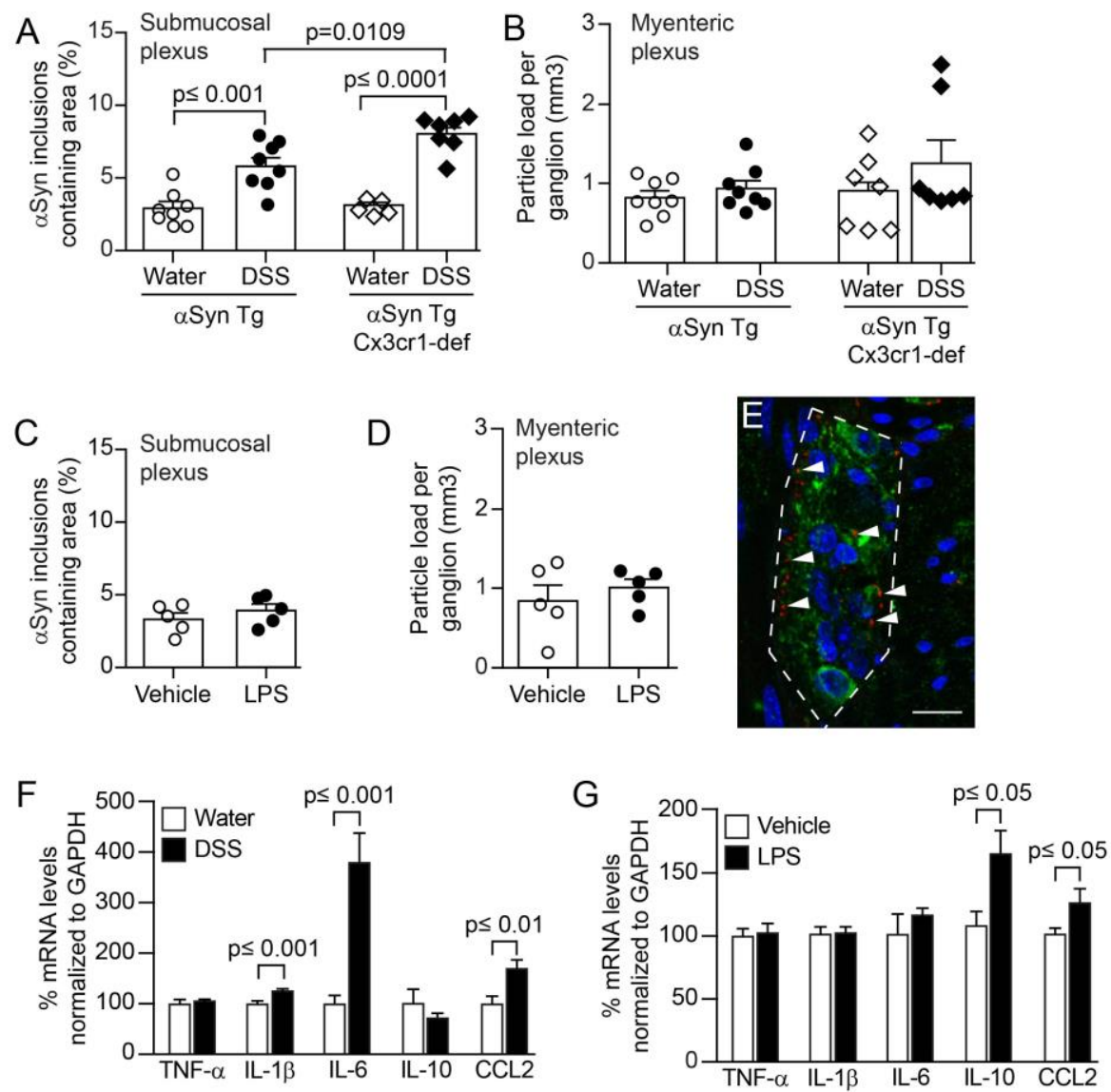

Fig. 3 Colitis induced by peroral DSS but not peritoneal LPS enhances $\alpha$ Syn accumulation in

the colonic submucosal plexus of hemizygous (Thy1)-h[A30P] $[$ Syn transgenic mice and can be

aggravated by lack of Cx3cr1 signaling. Mice received in an acute paradigm either peroral 5\% DSS in their drinking water or intraperitoneally $0.5 \mathrm{mg} / \mathrm{kg}$ LPS. Effects of the two agents in the ENS was compared to effects induced by vehicle (see Figure $2 \mathrm{C}$ for timelines). Stereological quantification of $\alpha$ Syn inclusions in the submucosal plexus as $\%$ area $(\mathbf{a}, \mathbf{c})$ and in the mucosal plexus as particle load per ganglion (b, d) (Two-way ANOVA with Tukey post hoc test; covariates genotype and treatment paradigm). e Representative 2D stacks of confocal images of intracellular $\alpha$ Syn inclusions (red, human $\alpha$ Syn specific monoclonal antibody clone 211 ; arrow heads pointing to some selected inclusions) in a ganglion of the myenteric plexus (green, peripherin) with cellular nuclei in blue (DAPI). Scale bar $50 \mu \mathrm{m}$. Gene expression analysis of selected cytokines in the colon of (Thy1)$\mathrm{h}[\mathrm{A} 30 \mathrm{P}] \alpha$ Syn transgenic mice that received either acute DSS (f) or LPS (g) compared to their respective vehicle or water controls. Note the strong increase in IL-6 and the lack of elevation of IL- 
10 in the DSS paradigm compared to the LPS paradigm indicating a different inflammatory colonic milieu despite the abundant leukocyte infiltration in both paradigms. $\mathrm{N}=5-8$ per group; mean and s.e.m.; Student's t-test between inflammatory agent and vehicle for individual cytokines.

Grathwohl et al., Figure 4
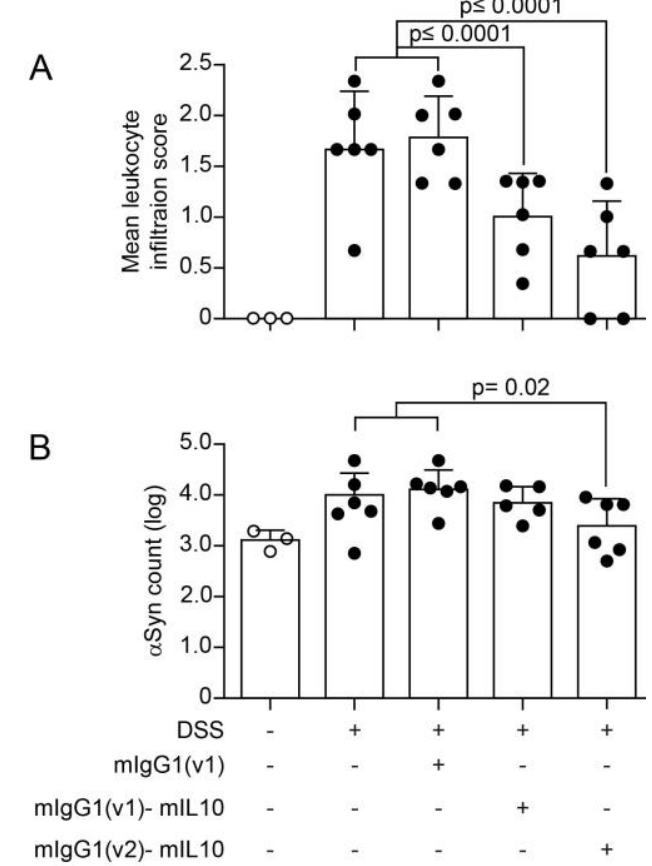

C

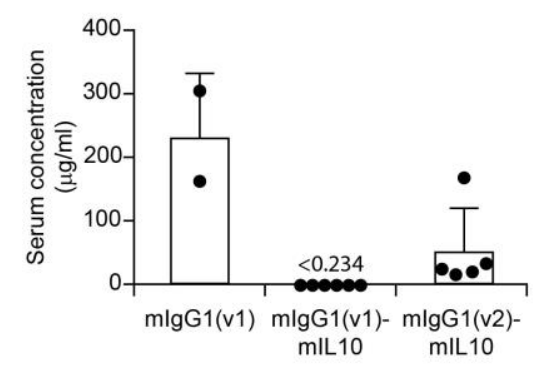

Fig. 4 Systemic IL-10 ameliorates DSS colitis and associated local $\alpha$ Syn accumulation in (Thy1)h[A30P] $\boldsymbol{\alpha S y n}$ transgenic mice. Two different recombinantly engineered and murine IgG1-fused forms of murine IL-10 (mIgG1(v1)-mIL10 and mIgG1(v2)-mIL10) were administered (150 $\mu \mathrm{g}$ per mouse i.p.) at the beginning of the acute DSS paradigm (5\%) in (Thy1)-h[A30P] Syn transgenic mice. Vehicle and the mIgG1(v1) alone served as untreated controls. a Leukocyte infiltration was assessed by visual scoring and (b) inclusion features of $\alpha$ Syn were stereologically and semiautomatically quantified and result log scaled for statistical analysis. Both the vehicle group and the 
mIgG1(v1) group had similar levels of leukocyte infiltration and $\alpha$ Syn inclusions and were merged for

1063 the statistical analysis to compare with the IL-10 treated groups. Both forms of IL-10 ameliorated

1064 leukocyte infiltration whereas mIgG1(v2)-mIL10 also blocked the appearance of $\alpha$ Syn inclusions significantly ( $\mathrm{n}=3-6$ per group; mean and s.e.m.; one-way ANOVA and Tukey post hoc test). a Persistent exposure mIgG1(v2)-mIL10 versus mIgG1(v1)-mIL10 (lower limit of detection is indicated at $<0.234 \mu \mathrm{g} / \mathrm{ml}$ ) as measured in serum at the end of the in vivo phase corresponds with beneficial treatment effects on $\alpha$ Syn readout observed above. The mIgG1(v1) was only measured in two mice.

Grathwohl et al., Figure 5
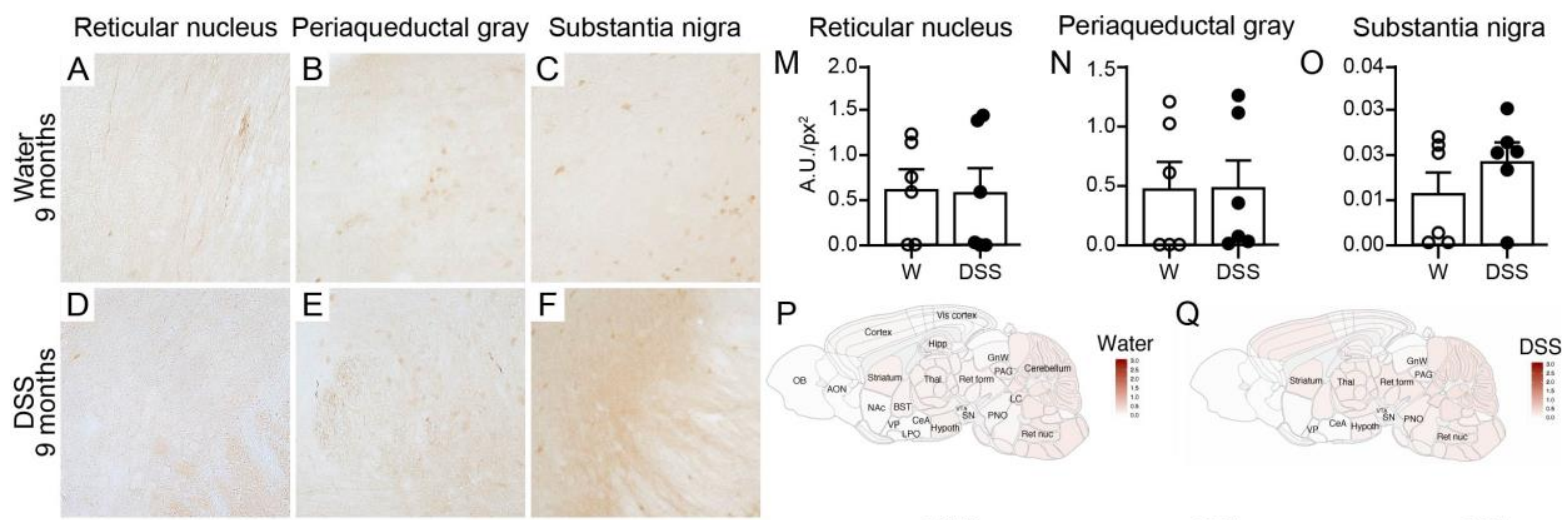

Q
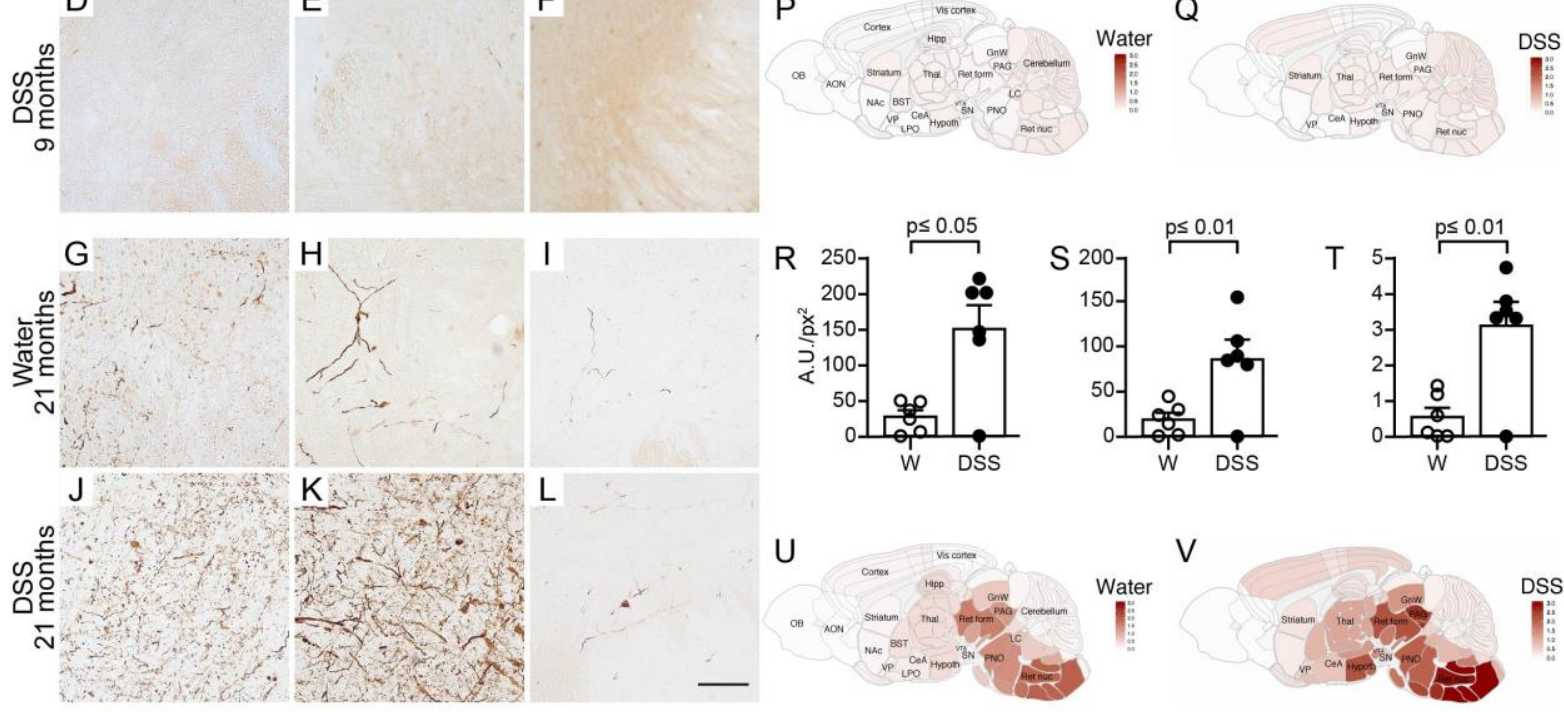

U
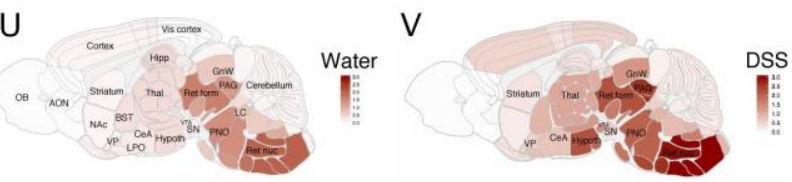

Fig. 5 A single chronic DSS colitis insult causes an age-dependent accumulation of proteinase $K$ resistant pSer129-aSyn in various brain regions of (Thy1)-h[A30P] $\alpha$ Syn transgenic mice. A 3week chronic increasing dose DSS paradigm was performed with 3-month old (Thy1)-h[A30P] $\alpha$ Syn transgenic mice. After recovering and further aging, various brain regions were analyzed for proteinase K resistant pSer129- $\alpha$ Syn immunoreactivity in 9-month (a-f) and 21-month old (g-l) mice, 
respectively. The dark brown features in G-L indicate proteinase K resistant pSer129- $\alpha$ Syn. They are barely visible in A-F. Densitometric quantification of pSer129- $\alpha$ Syn immunoreactivity in different brain regions in 9-month (m-o) and 21-month old mice (r-t) (n=6 mice per group). The two orders of magnitude different y-axes between $\mathbf{m}-\mathbf{o}$ and $\mathbf{r}-\mathbf{t}$ confirm the visual impression in panel a-l. One 21month old DSS-treated mouse was excluded from analysis due to presumed failed treatment; it is included in the graphs. Statistical analyses were performed using negative-binomial mixed-effects models adjusting for multiple comparisons. Representative heatmap of the average distribution scores of pSer129- $\alpha$ Syn immunoreactivity for each treatment group in varying brain regions in all the 9month (p-q) and 21-month old (u-v) mice was generated in a sagittal mouse brain ( $\mathrm{n}=10$ mice per group). Scale bars: $500 \mu \mathrm{m}$.

Grathwohl et al., Figure 6
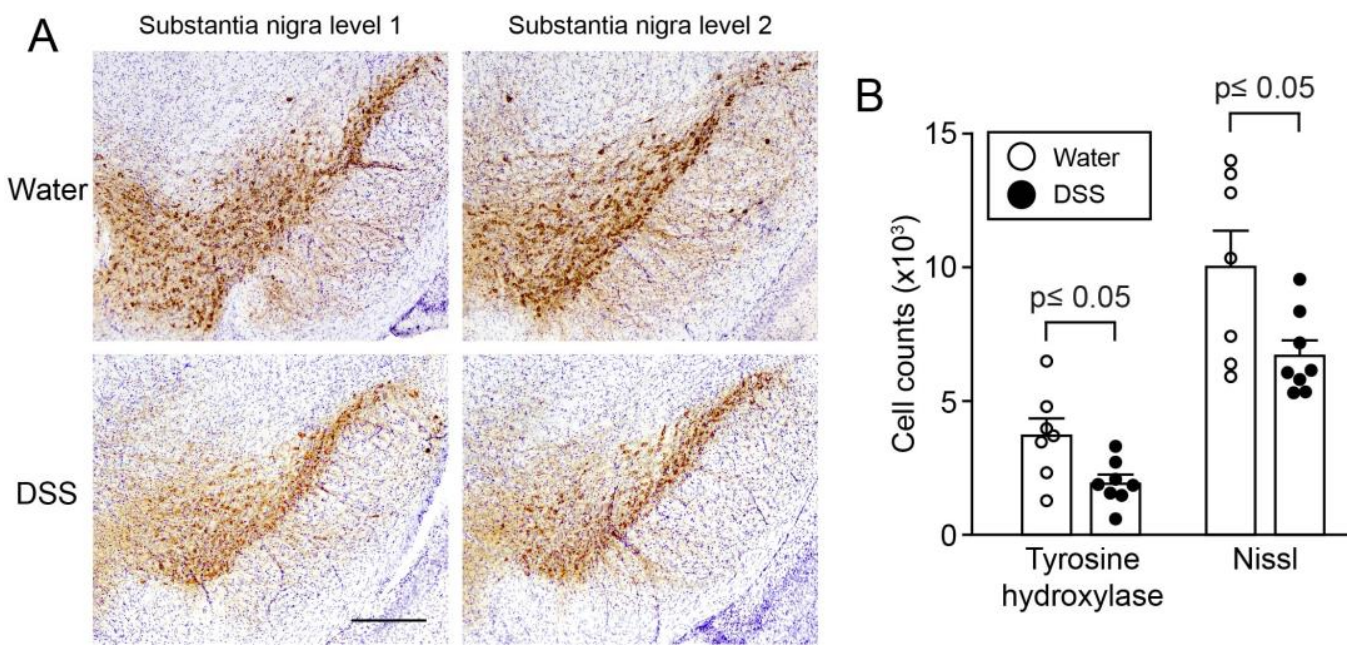

Fig. 6 Loss of tyrosine hydroxylase and Nissl positive cells in the substantia nigra of (Thy1)h[A30P] $\alpha$ Syn transgenic mice at 21 months of age, 18 months after DSS colitis. (Thy1)$\mathrm{h}[\mathrm{A} 30 \mathrm{P}] \alpha$ Syn transgenic mice that were exposed to a chronic DSS-colitis paradigm at 3 months and were aged to 21 months showed a significant loss of mean count of Nissl-positive cells with tyrosine hydroxylase (TH) immunoreactivity and cellular Nissl staining in the substantia nigra compared to age-matched littermate mice in the group that did not experience DSS colitis (water). a Representative 
1097 cells positive for TH or Nissl ( $\mathrm{n}=7-8$ mice per group). Statistical analyses of the TH dataset were

1098 performed using Student's T-test, while Welch's T-test was used for the Nissl dataset to adjust for 1099 unequal variances. Scale bar: $500 \mu \mathrm{m}$.

1100 
Specific immune modulation of experimental colitis drives enteric alpha-synuclein accumulation and triggers age-related Parkinson-like brain pathology

Stefan Grathwohl ${ }^{1}$, Emmanuel Quansah ${ }^{2}$, Nazia Maroof ${ }^{1}$, Jennifer A. Steiner ${ }^{2}$, Liz Spycher ${ }^{1}$, Fethallah Benmansour ${ }^{3}$, Gonzalo Duran-Pacheco ${ }^{4}$, Juliane Siebourg-Polster ${ }^{4}$, Krisztina Oroszlan-Szovik ${ }^{1}$, Helga Remy ${ }^{1}$, Markus Haenggi ${ }^{1}$, Marc Stawiski ${ }^{1}$, Matthias Sehlhausen ${ }^{4}$, Pierre Maliver ${ }^{4}$, Andreas Wolfert ${ }^{5}$, Thomas Emrich ${ }^{5}$ Zachary Madaj ${ }^{2}$, Arel Su${ }^{4}$, Martha L. Escobar Galvis ${ }^{2}$, Christoph Mueller ${ }^{6}$, Annika Herrmann $^{4}$, Patrik Brundin ${ }^{2 *}$, and Markus Britschgi ${ }^{1 *}$

${ }^{1}$ Roche Pharma Research and Early Development, Neuroscience and Rare Diseases Research, Roche Innovation Center Basel, F. Hoffmann-La Roche Ltd, Grenzacherstrasse 124, Basel, Switzerland

${ }^{2}$ Center for Neurodegenerative Science, Van Andel Research Institute, 333 Bostwick Ave. NE, Grand Rapids, MI, USA

${ }^{3}$ Roche Pharma Research and Early Development, pREDi, Roche Innovation Center Basel, F. Hoffmann-La Roche Ltd, Grenzacherstrasse 124, Basel, Switzerland

${ }^{4}$ Roche Pharma Research and Early Development, Pharmaceutical Sciences, Roche Innovation Center Basel, F. Hoffmann-La Roche Ltd, Grenzacherstrasse 124, Basel, Switzerland

${ }^{5}$ Roche Pharma Research and Early Development, Pharmaceutical Sciences, Roche Innovation Center Munich, Roche Diagnostics GmbH, Nonnenwald 2, Penzberg, Germany

${ }^{6}$ Institute of Pathology, University of Bern, Murtenstrasse 31, Bern, Switzerland

\section{Corresponding authors:}

* Markus Britschgi, Roche Pharma Research and Early Development, Neuroscience and Rare Diseases Research, Roche Innovation Center Basel, F. Hoffmann-La Roche Ltd, Grenzacherstrasse 124, 4070 Basel, Switzerland

Tel: +41616879116

Email: markus.britschgi@roche.com Tel: +1 616.234.5312

Email: patrik.brundin@vai.org 
Grathwohl et al., Suppl. Fig. 1

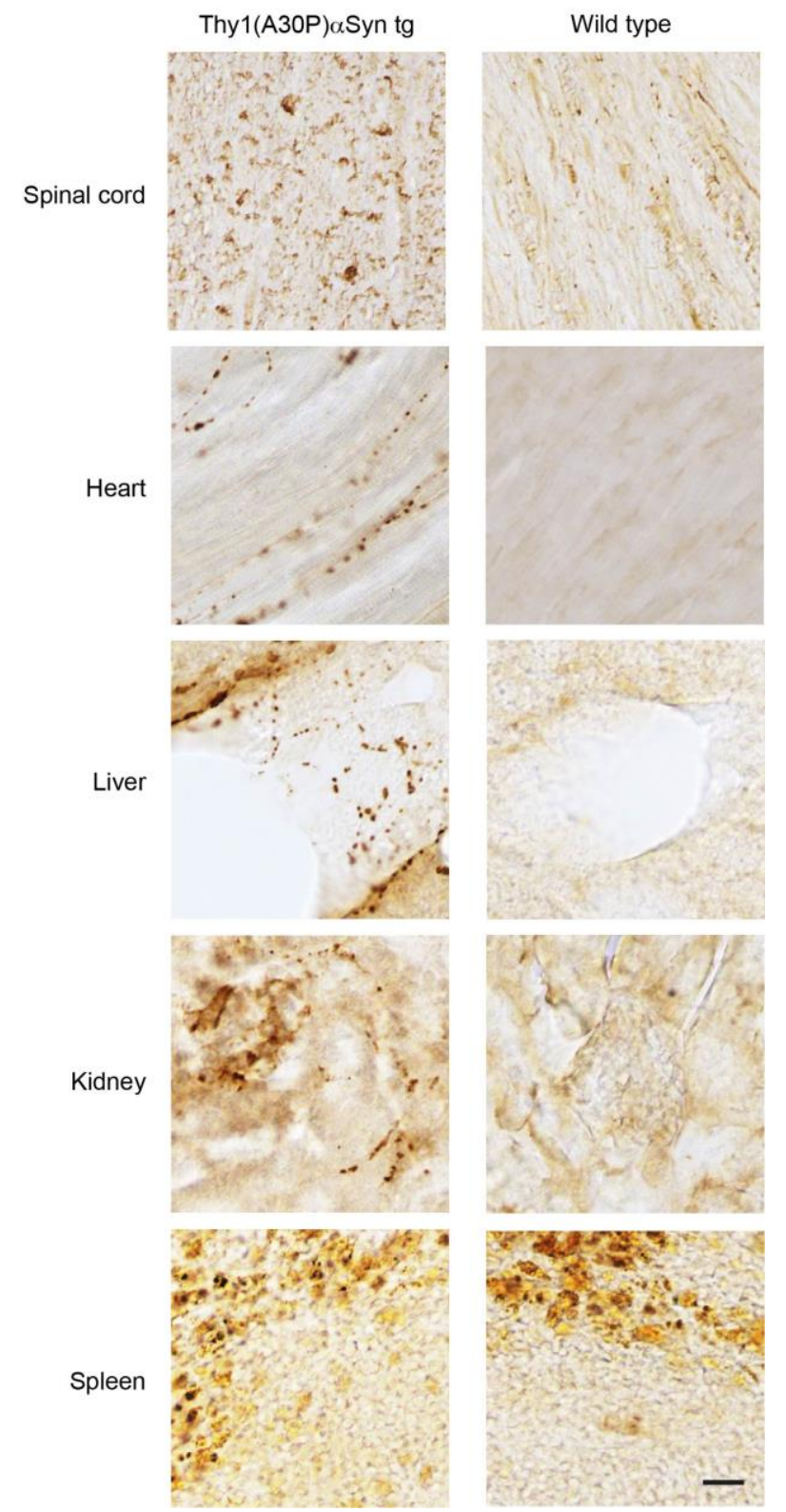

Suppl. Fig. 1 Alpha-synuclein is expressed in majority of organs in wildtype and (Thy1)-

$1137 \mathbf{h}[\mathbf{A 3 0 P}] \boldsymbol{\alpha S y n}$ transgenic mice. Immunohistochemical detection of human $\alpha$ Syn (clone LB509 monoclonal antibody) in (Thy1)-h[A30P] $\alpha$ Syn transgenic mice or of endogenous murine $\alpha$ Syn in wildtype mice (syn1 monoclonal antibody) in various organs. Note the typical dot-like structures of the human $\alpha$ Syn in the transgenic mice reminiscent of neuritic inclusions and the very low expression of endogenous murine $\alpha$ Syn in the wildtype mice. The pronounced brownish staining in the spleen is due to the abundant iron which is exposed by the chromogenic staining method. Note, thymocytes in

1143 the spleen do not stain for human $\alpha$ Syn supporting the selectivity of the expression of the transgenic 
human $\alpha$ Syn under the modified Thy1.2 cassette; e.g. not expressed in thymocytes (See Kahle et al.;

1145 reference 26). $\mathrm{n}=3$ per group Scale bar $20 \mu \mathrm{m}$.

Grathwohl et al., Suppl. Fig. 2
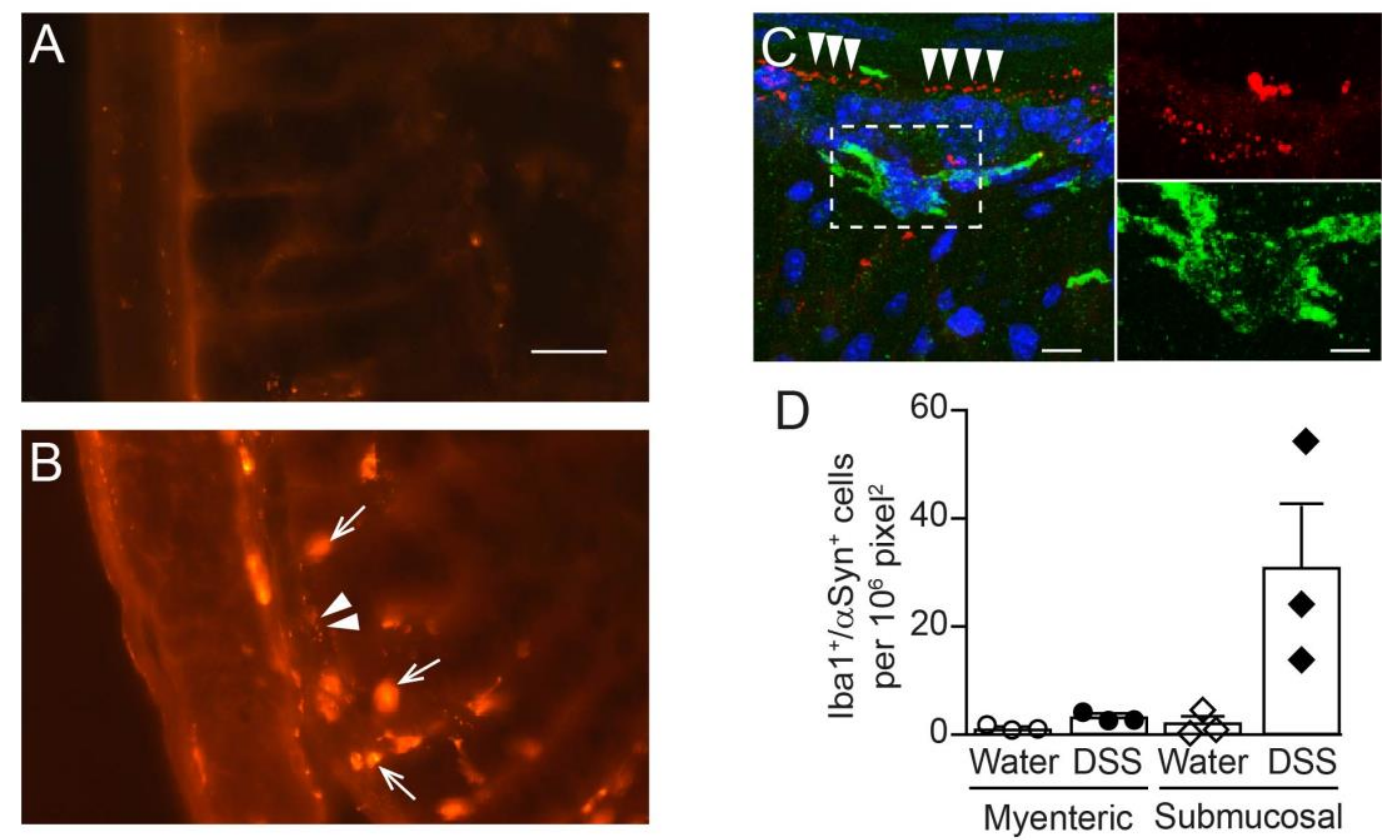

Suppl. Fig. 2 Alpha-synuclein co-localizes with ENS and macrophages upon DSS colitis in $\alpha$ Syn

transgenic mice. (A, B) Immunofluorescence image of $\alpha$ Syn staining in colonic region of (Thy1)-

$\mathrm{h}[\mathrm{A} 30 \mathrm{P}] \alpha$ Syn transgenic mice on water $(\mathbf{A})$ or after acute DSS colitis $(2.5 \%)(\mathbf{B})$. Note the small dotted structures of the typical $\alpha$ Syn inclusions in the submucosal plexus (arrow heads) and the large features of immunoreactivity which localize to infiltrating leukocytes (arrows; identified by their typical cellular morphology), similar to what was observed in IBD patients in Figure 1. Scale bar 100 $\mu \mathrm{m}$. (C) 2D stacks and close-up of confocal images co-localizing $\alpha$ Syn (red) with the macrophage marker Iba-1 (green) in the colon of a (Thy1)-h[A30P] $\alpha$ Syn transgenic mouse after DSS colitis. Note the dotted structures of the typical $\alpha$ Syn inclusions in the submucosal plexus (arrow heads). Scale bar

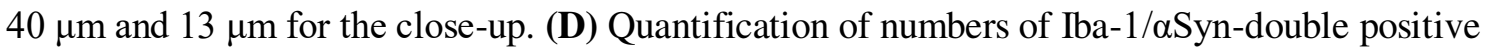
macrophages ( $\mathrm{n}=3$ per group; mean and s.e.m.) 
Grathwohl et al., Suppl. Fig. 3

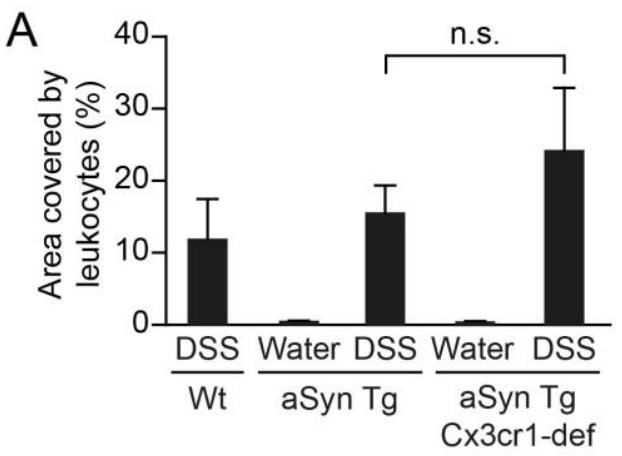

B

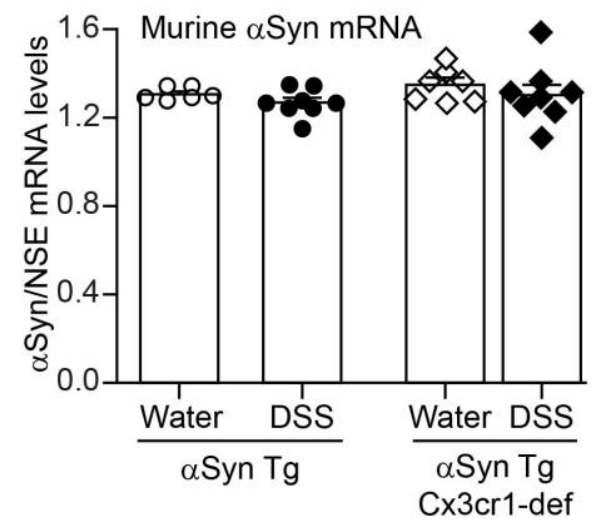

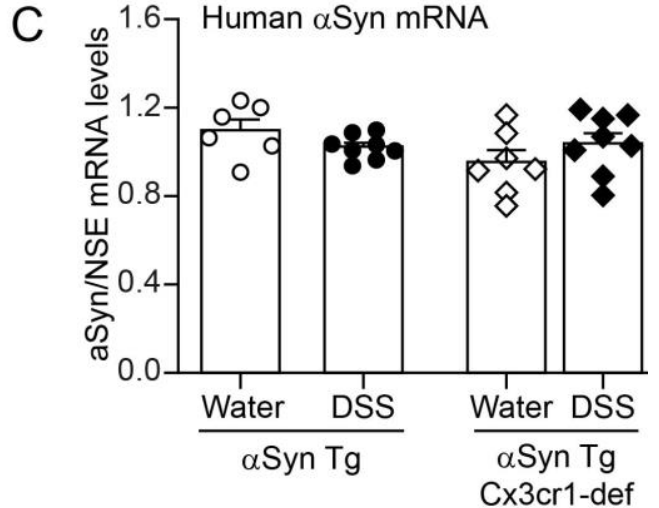

Suppl. Fig. 3 Expression of endogenous and transgenic $\alpha$ Syn in the colon is unchanged after acute DSS colitis. a Administration of DSS (acute 5\%) induces leukocyte infiltration in wildtype, (Thy1)-h[A30P] $\alpha$ Syn transgenic ( $\alpha$ Syn Tg) and Cx3crl-deficient (Thy1)-h[A30P] $\alpha$ Syn transgenic mice ( $\alpha$ Syn Tg Cx3cr1-def) (Two-way ANOVA with Tukey post hoc test; covariates genotype and treatment paradigm). Expression levels of endogenous murine (b) or transgenic human $\alpha \mathrm{Syn}$ (c) mRNA were normalized to mRNA levels of the neuronal marker neuron specific enolase (NSE) to correct for potential neuronal loss $(n=5-8$ per group; mean and s.e.m). 
Grathwohl et al., Suppl. Fig. 4
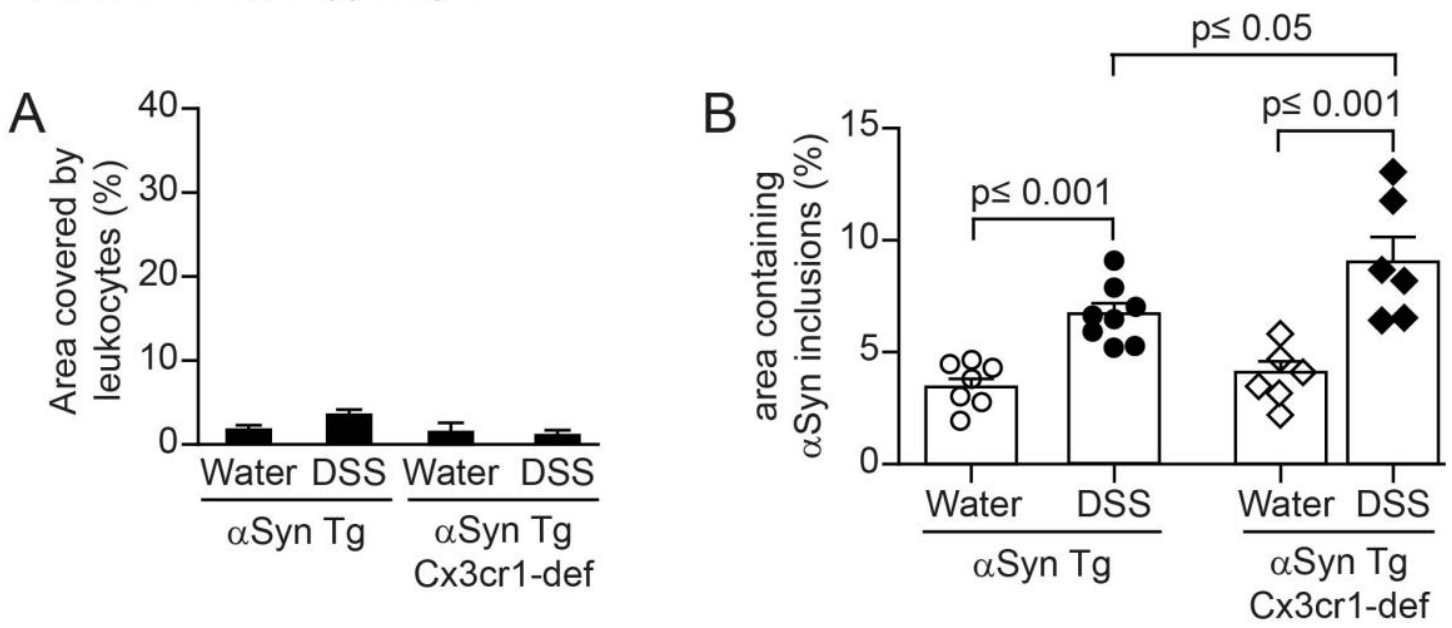

1176

1177 Suppl. Fig. 4 DSS colitis induced accumulation of $\alpha$ Syn in submucosal plexus of (Thy1)-

$1178 \mathbf{h}[\mathbf{A 3 0 P}] \boldsymbol{\alpha S y n}$ transgenic mice remain stable long after recovery. A 4-week chronic DSS paradigm was performed with (Thy1)-h[A30P] $\alpha$ Syn ( $\alpha$ Syn Tg) and (Thy1)-h[A30P] $\alpha$ Syn crossed with Cx3cr1def mice ( $\alpha$ Syn Tg Cx3cr1-def). After recovery for 2 months and thus analysis at the age of 6 months,

1181 a the colon was inspected for signs of inflammation (area covered by leukocytes) and $\mathbf{b}$ amount of

$1182 \alpha$ Syn inclusions (area containing $\alpha$ Syn inclusions). $N=6-8$ per group. Statistical analyses were

1183 performed using two-way ANOVA with Tukey post hoc testing; covariates genotype and treatment 1184 paradigm. 
Grathwohl et al., Figure S5a

Aged up to 9 months (6 months post a 3-week chronic increasing dose DSS colitis paradigm at the age of 3 months)

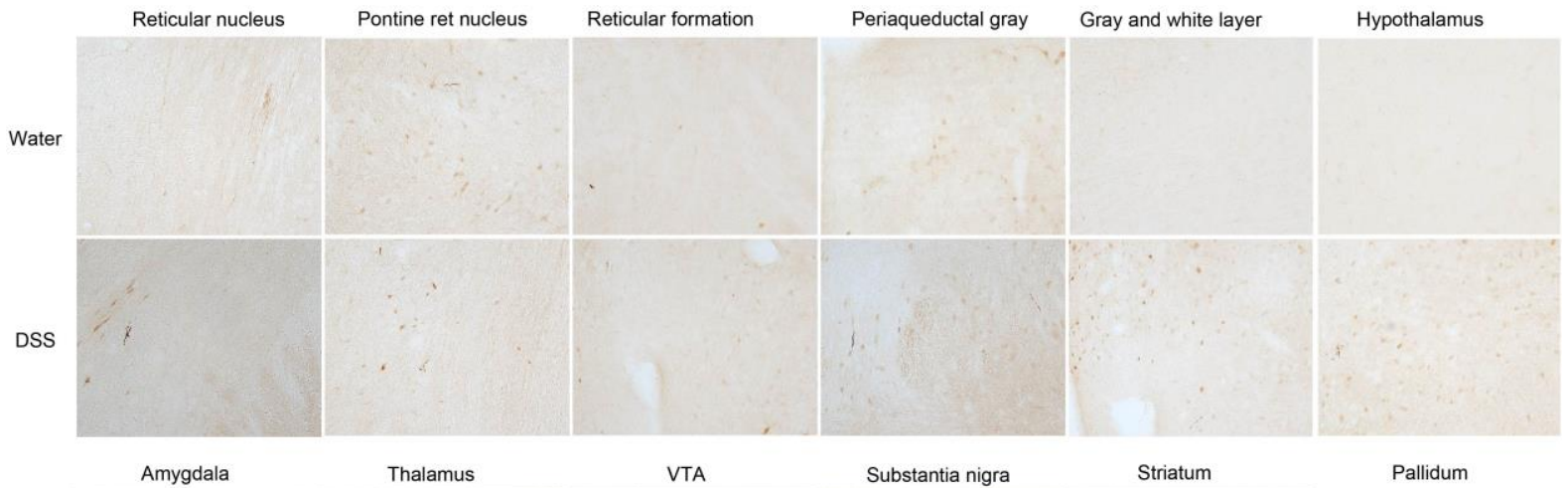
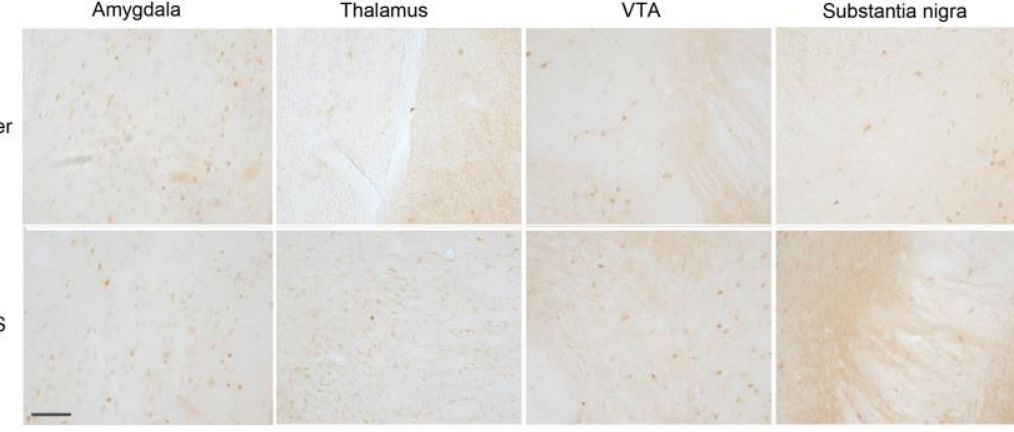

Grathwohl et al., Suppl. Fig. 5b

Aged up to 21 months (18 months post a 3-week chronic increasing dose DSS colitis paradigm at the age of 3 months)

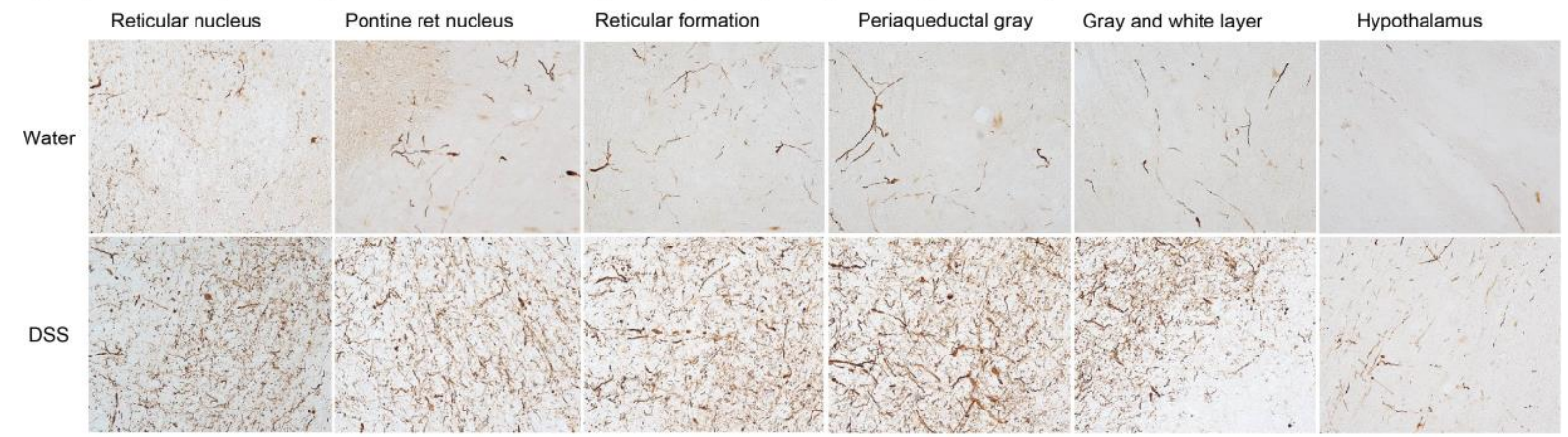

Amygdala

Thalamus

VTA

Substantia nigra

Striatum

Pallidum
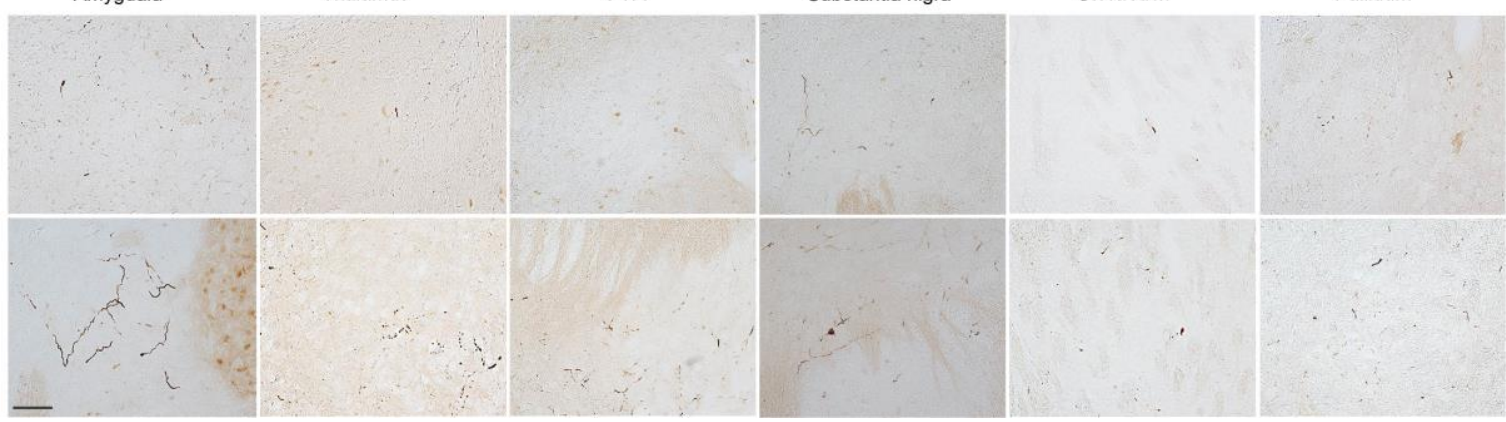
Grathwohl et al., Suppl. Fig. 5c

Quantification of Suppl. Fig. 5b
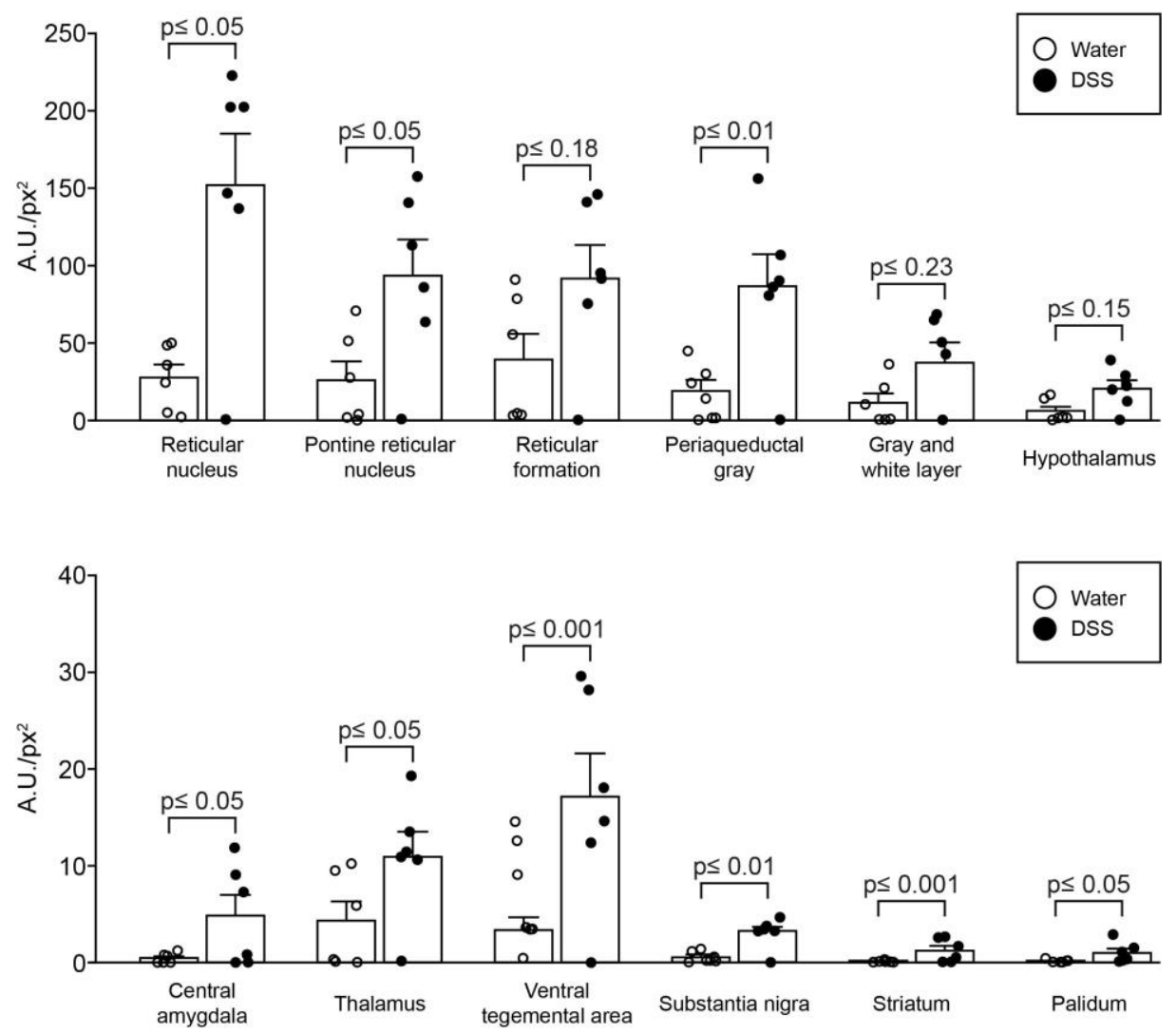

Suppl. Fig. 5 Development of $\alpha$ Syn pathology in the brain of 21-month aged (Thy1)-

$\mathrm{h}[\mathrm{A30P}] \alpha$ Syn transgenic mice upon DSS colitis at young age.

A 3-week increasing dose chronic DSS paradigm was performed with 3-month old (Thy1)-

$\mathrm{h}[\mathrm{A} 30 \mathrm{P}] \alpha$ Syn transgenic mice. After recovery and further aging under normal conditions, various brain regions were analyzed for proteinase K resistant pSer129- $\alpha$ Syn immunoreactivity in 9-month (a, cohort 1) and 21-month old (b, cohort 2) mice. c Densitometric quantification of pSer129- $\alpha$ Syn immunoreactivity in different brain regions in the 21-month old (from Suppl. Fig 5b) mice were measured ( $\mathrm{n}=6$ mice/group). Statistical analyses were performed using linear mixed-effects model adjusting for multiple comparisons. A.U./px ${ }^{2},=$ mean grey value $\mathrm{x}$ area stained/total area assessed. Scale bars: $500 \mu \mathrm{m}$. 

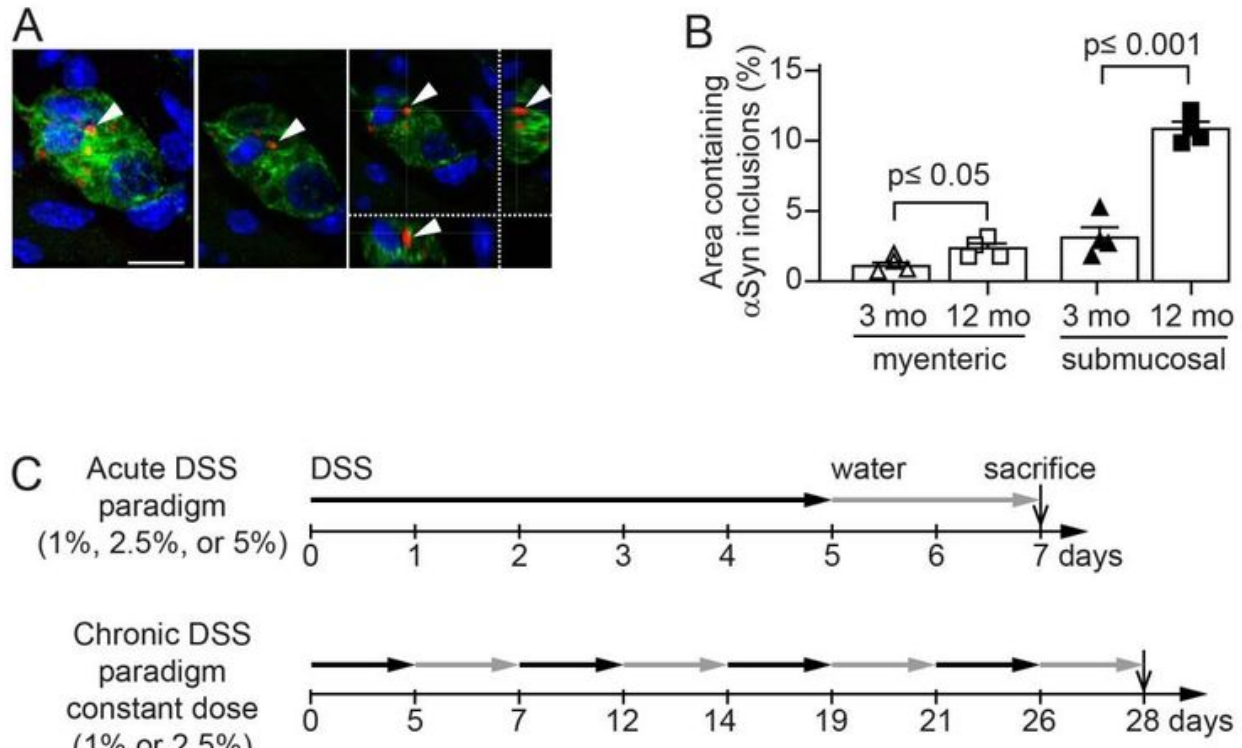

$(1 \%$ or $2.5 \%)$
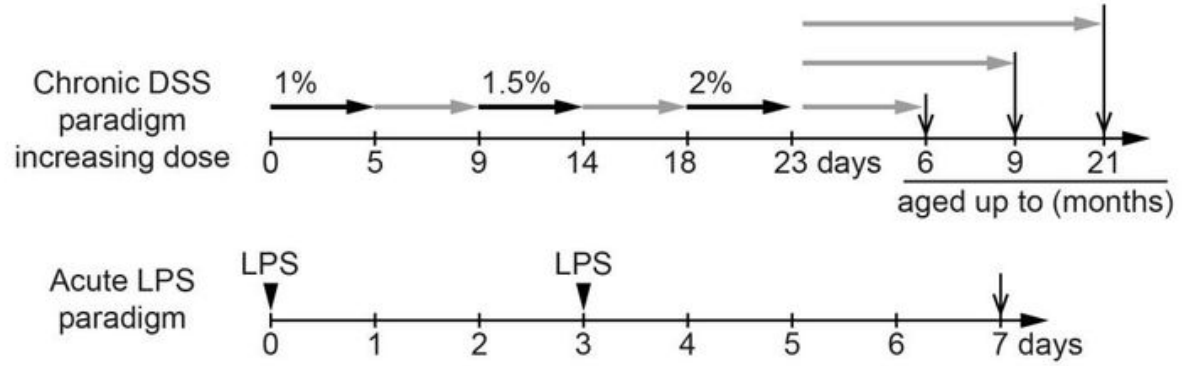

D
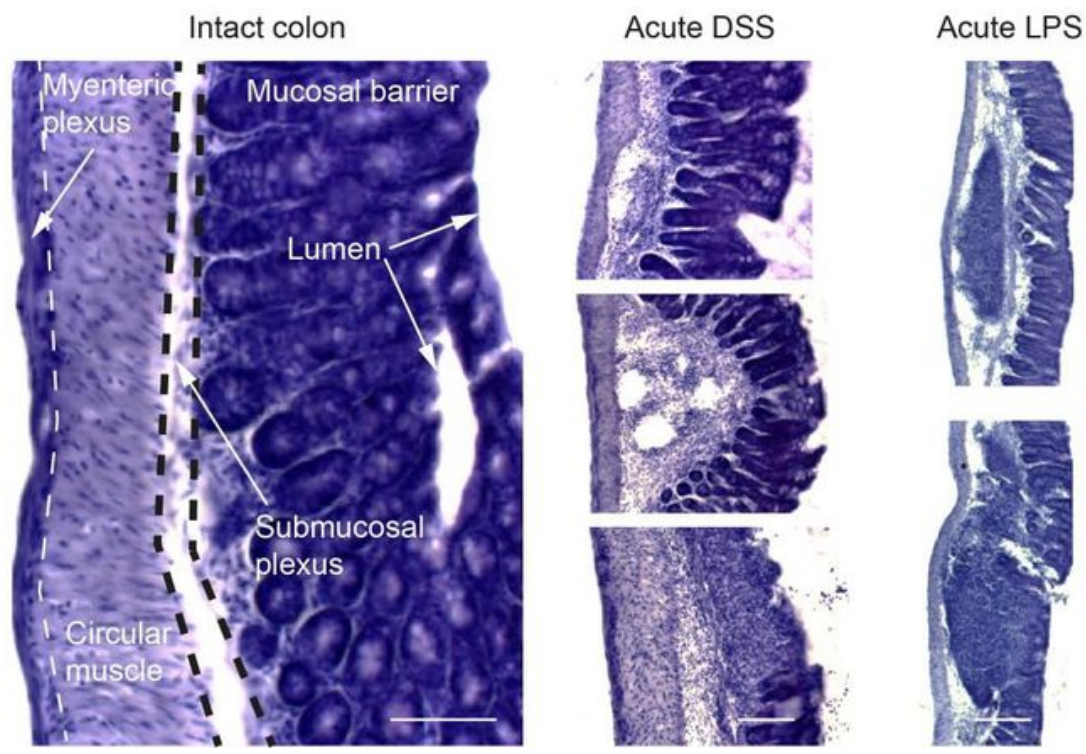

\section{Figure 1}

Age dependent increase of intracellular aSyn accumulation in enteric nervous system of hemizygous (Thy1)-h[A30P]aSyn transgenic mice and setup of the experimental colitis paradigms. a Confocal microscopy imaging of the inclusions of human aSyn (red, antibody clone 211; human aSyn specific) 
within the ganglia of the submucosal plexus (green, peripherin; blue, DAPI/nuclei) of hemizygous (Thy1)$\mathrm{h}[\mathrm{A} 30 \mathrm{P}] \mathrm{aSyn}$ transgenic mice. Arrowhead points to one of the typical irregularly sized and shaped aSyn inclusion bodies visualized in 2D z-stacks of rotated confocal images. Scale bar, $100 \mu \mathrm{m}$. b Stereological quantification of normally occurring human aSyn inclusions in the myenteric and submucosal plexuses of 3 and 12 months old hemizygous (Thy 1$)$-h[A30P]aSyn transgenic mice ( $n=4$ per group; mean and S.E.M. are shown; Student t-test between the two age groups in each region). c Setup of experimental colitis paradigms employing dextran sulfate sodium (DSS, per os in drinking water). Additionally, peripheral inflammation was induced by bacterial lipopolysaccharide (LPS, intraperitoneal injection). After some chronic DSS paradigms mice were aged on normal water up to 6, 9 or 21 months. Mice aged up to 9 or 21 months of age were analyzed for brain pathology d Hematoxylin staining of $35 \mu \mathrm{m}$ thick colon sections of 3 months old hemizygous (Thy1)-h[A30P]aSyn transgenic mice. Organizational layers of the intact colon (left panel). Representative images of various severity degrees of DSS-driven colitis from weak leukocyte infiltration (top panel of acute DSS) to more extensive leukocyte infiltration with mucosal ulceration (lowest panel of acute DSS). Note the different appearance of enteric inflammation in acute LPS-driven peripheral inflammation compared with DSS; e.g., confined immune cell clustering and lymphoid hyperplasia; intact mucosal layer. Scale bar $50 \mu \mathrm{m}$ (intact colon), $100 \mu \mathrm{m}$ (acute DSS), and 200 $\mu \mathrm{m}$ (LPS). 
A
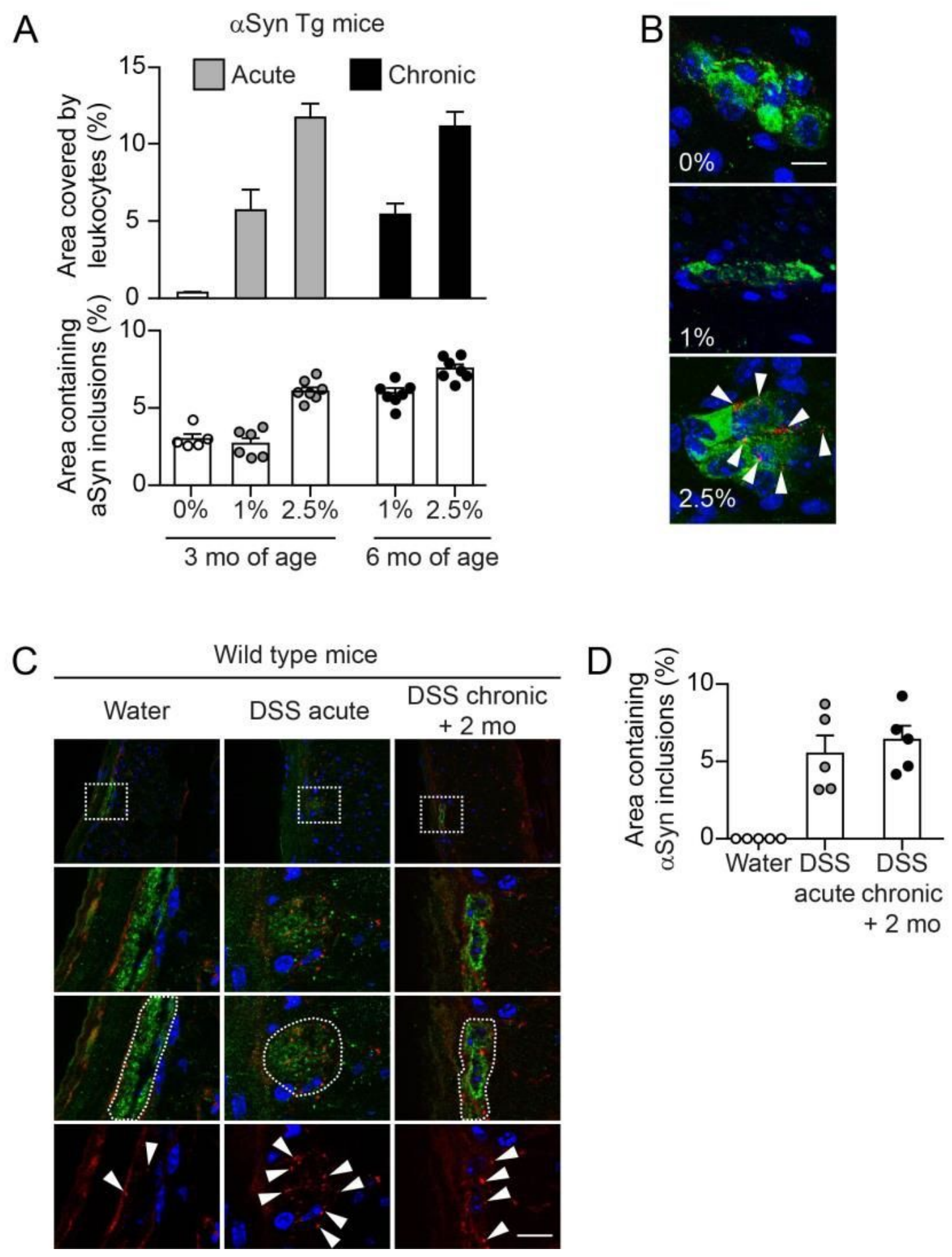

Figure 2

Colitis severity and duration-dependent aggravation of accumulation of aSyn inclusions in the colonic submucosal plexus of hemizygous (Thy1)-h[A30P]aSyn transgenic and wild type mice. a DSS dosedependent increase of leukocyte infiltration in the acute and chronic paradigm. The highest acute dose $(2.5 \%)$ and the two constant chronic doses led to an increase of aSyn inclusions in the submucosal plexus (stereological quantification of aSyn inclusions in the submucosal plexus of 3 and 6 months old 
hemizygous (Thy1)-h[A30P]aSyn transgenic mice; $n$ = 5-7 per group; mean and s.e.m. are shown). $b$ Representative 2D z-stacks of confocal images of increasing abundance of aSyn inclusions (red, humanaSyn specific monoclonal antibody clone 211) in a ganglion of the submucosal plexus (green, peripherin) with cellular nuclei in blue (DAPI) in the acute DSS paradigm. Arrow heads point to the typical irregularly sized and shaped aSyn inclusion bodies that accumulate Grathwohl et al. in the highest DSS dose. Scale bar $200 \mu \mathrm{m}$. c Overview of colonic region of 3-month-old wildtype mice (top row) exposed to water or acute DSS (5\%) with immunofluorescence analysis of murine aSyn load in the colon performed immediately after colitis or exposed to constant chronic DSS (2.5\%) and analysis after aging on normal water for another 2 months. White dotted rectangles in the top row indicate the area that was zoomed out below illustrating in more detail the murine aSyn inclusions (red, rodent aSyn cross-reactive monoclonal antibody syn1/clone 42) in the submucosal plexus (green, peripherin). The lower three rows show DAPI and aSyn inclusions with and without the peripherin channel. The white dotted circled area illustrates the peripherin-positive area that was analyzed for aSyn inclusion bodies (arrow heads in bottom row). Scale bar for the lower three panels $200 \mu \mathrm{m}$. d Stereological quantification of murine aSyn inclusions in the submucosal plexus of wildtype mice right after acute DSS colitis or after 2 months of recovery from a 4week chronic DSS colitis ( $n=5$ per group). Note the regularly arranged and smoothly distributed immunoreactivity for the physiological aSyn with barely any inclusion bodies in the intact enteric nerves of the water group. Statistical analysis for aSyn accumulation was omitted as the noticeable differences between the means are self-evident (error bars indicate standard error of the mean) and an indication for an estimation for significance would be futile. 

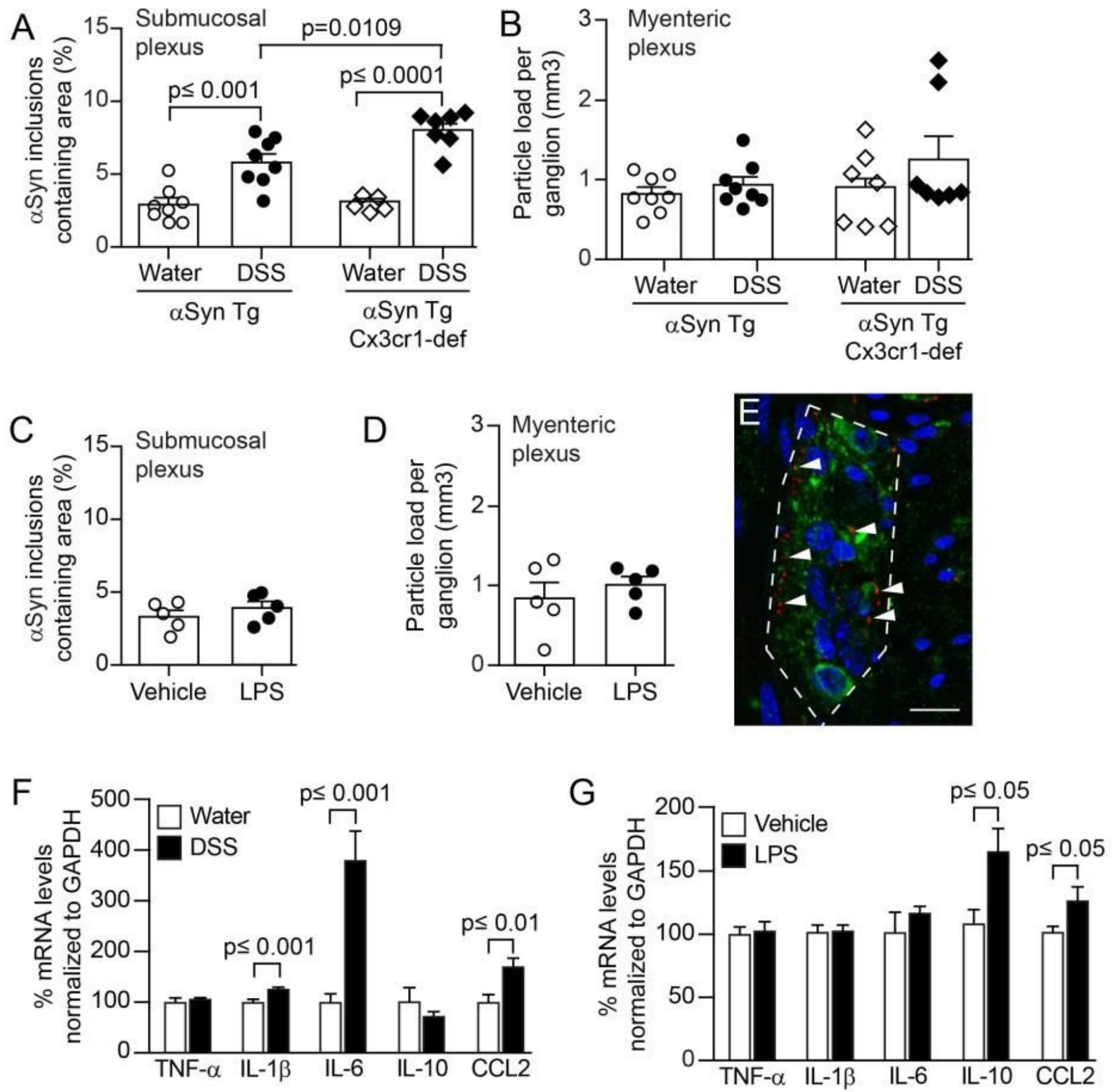

Figure 3

Colitis induced by peroral DSS but not peritoneal LPS enhances aSyn accumulation in the colonic submucosal plexus of hemizygous (Thy1)-h[A30P]aSyn transgenic mice and can be aggravated by lack of $\mathrm{Cx} 3 \mathrm{cr} 1$ signaling. Mice received in an acute paradigm either peroral 5\% DSS in their drinking water or intraperitoneally $0.5 \mathrm{mg} / \mathrm{kg}$ LPS. Effects of the two agents in the ENS was compared to effects induced by vehicle (see Figure $2 \mathrm{C}$ for timelines). Stereological quantification of 1aSyn inclusions in the 
submucosal plexus as \% area (a, c) and in the mucosal plexus as particle load per ganglion (b, d) (Twoway ANOVA with Tukey post hoc test; covariates genotype and treatment paradigm). e Representative 2D stacks of confocal images of intracellular aSyn inclusions (red, human aSyn specific monoclonal antibody clone 211; arrow heads pointing to some selected inclusions) in a ganglion of the myenteric plexus (green, peripherin) with cellular nuclei in blue (DAPI). Scale bar $50 \mu \mathrm{m}$. Gene expression analysis of selected cytokines in the colon of (Thy1)- h[A30P]aSyn transgenic mice that received either acute DSS (f) or LPS (g) compared to their respective vehicle or water controls. Note the strong increase in IL-6 and the lack of elevation of IL-Grathwohl et al. 10 in the DSS paradigm compared to the LPS paradigm indicating a different inflammatory colonic milieu despite the abundant leukocyte infiltration in both paradigms. $\mathrm{N}=$ 5-8 per group; mean and s.e.m.; Student's t-test between inflammatory agent and vehicle for individual cytokines. 


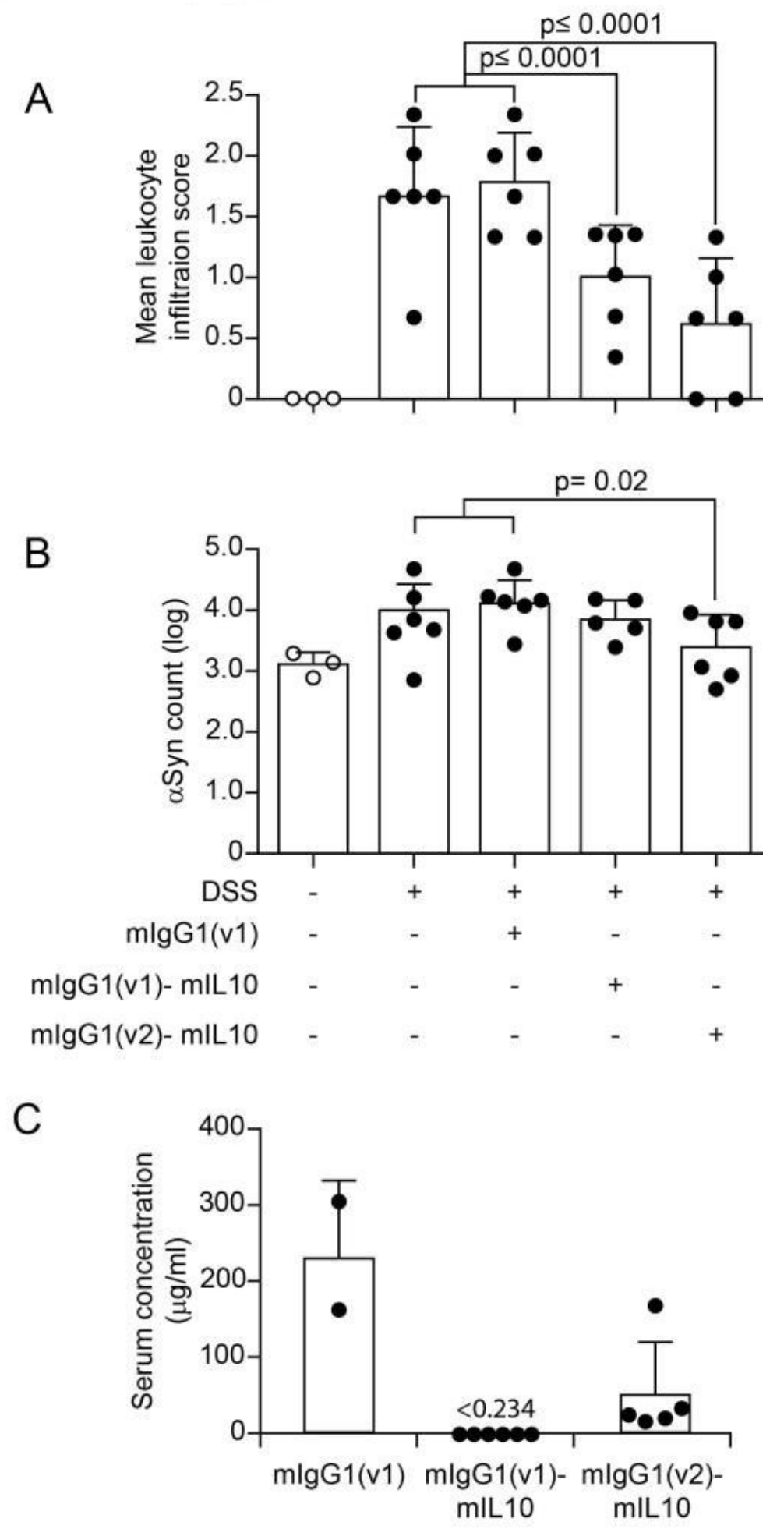

\section{Figure 4}

Systemic IL-10 ameliorates DSS colitis and associated local aSyn accumulation in (Thy 1)- h[A30P]aSyn transgenic mice. Two different recombinantly engineered and murine IgG1-fused forms of murine IL-10 (mlgG1(v1)-mIL10 and mlgG1(v2)-mIL10) were administered (150 $\mu$ g per mouse i.p.) at the beginning of the acute DSS paradigm (5\%) in (Thy1)-h[A30P]aSyn transgenic mice. Vehicle and the mlgG1(v1) alone served as untreated controls. a Leukocyte infiltration was assessed by visual scoring and (b) inclusion 
features of aSyn were stereologically and semi-automatically quantified and result log scaled for statistical analysis. Both the vehicle group and the Grathwohl et al. mlgG1(v1) group had similar levels of leukocyte infiltration and aSyn inclusions and were merged for the statistical analysis to compare with the IL-10 treated groups. Both forms of IL-10 ameliorated leukocyte infiltration whereas mlgG1(v2)-mIL10 also blocked the appearance of aSyn inclusions significantly ( $n=3-6$ per group; mean and s.e.m.; oneway ANOVA and Tukey post hoc test). a Persistent exposure mlgG1(v2)-mIL10 versus mlgG1(v1)-mIL10 (lower limit of detection is indicated at $<0.234 \mu \mathrm{g} / \mathrm{ml}$ ) as measured in serum at the end of the in vivo phase corresponds with beneficial treatment effects on aSyn readout observed above. The mlgG1(v1) was only measured in two mice.

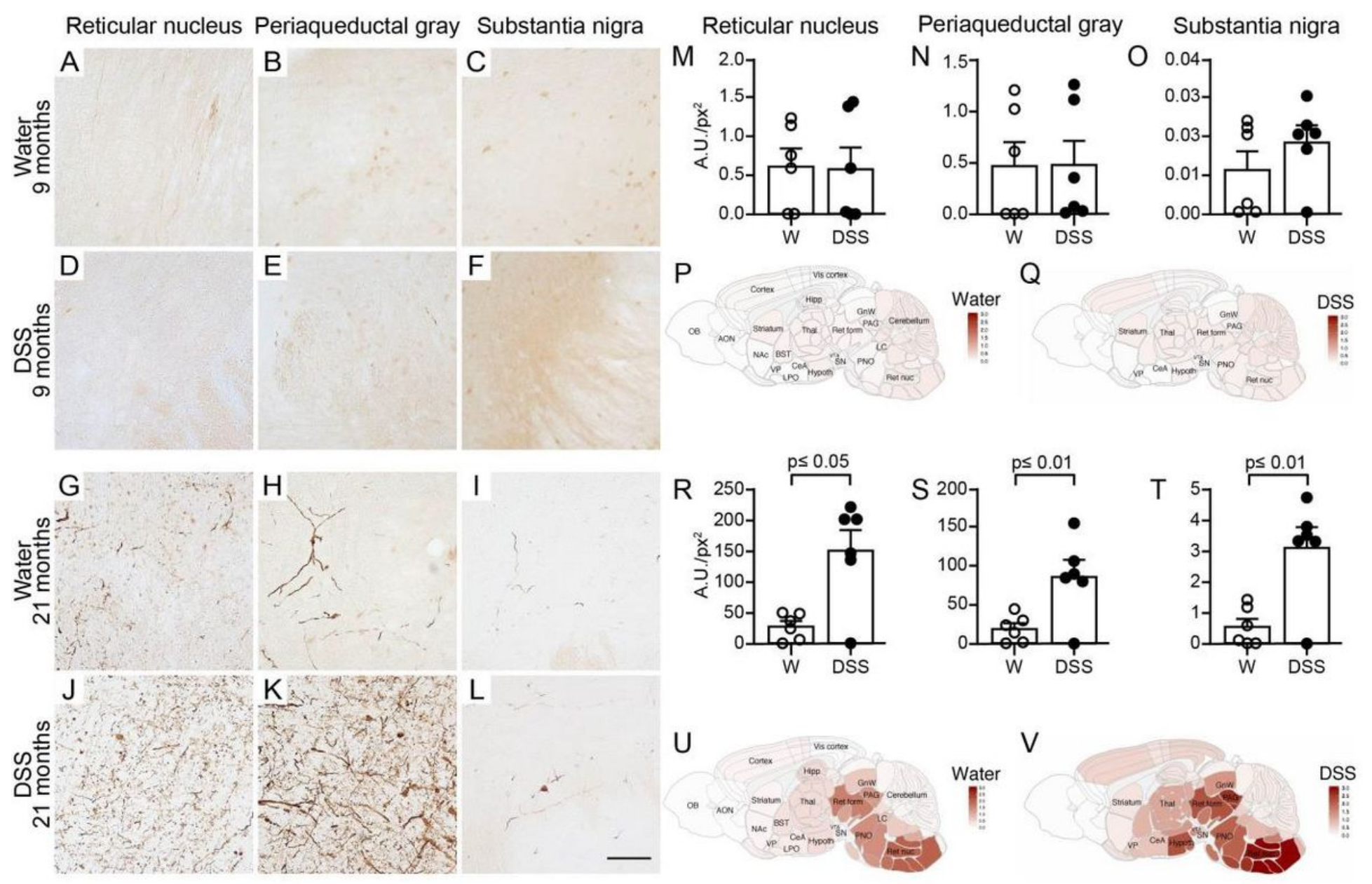

Figure 5

A single chronic DSS colitis insult causes an age-dependent accumulation of proteinase $\mathrm{K}$ resistant pSer129-aSyn in various brain regions of (Thy1)-h[A30P]aSyn transgenic mice. A 3-week chronic increasing dose DSS paradigm was performed with 3-month old (Thy1)-h[A30P]aSyn transgenic mice. After recovering and further aging, various brain regions were analyzed for proteinase $\mathrm{K}$ resistant pSer129-aSyn immunoreactivity in 9-month (a-f) and 21-month old (g-l) mice, Grathwohl et al. Page respectively. The dark brown features in G-L indicate proteinase $\mathrm{K}$ resistant pSer129-aSyn. They are 
barely visible in A-F. Densitometric quantification of pSer129-aSyn immunoreactivity in different brain regions in 9-month ( $\mathrm{m}-\mathrm{o})$ and 21-month old mice ( $\mathrm{r}-\mathrm{t})$ ( $\mathrm{n}=6$ mice per group). The two orders of magnitude different $y$-axes between $\mathrm{m}-\mathrm{o}$ and $\mathrm{r}$-t confirm the visual impression in panel a-I. One 21-month old DSStreated mouse was excluded from analysis due to presumed failed treatment; it is included in the graphs. Statistical analyses were performed using negative-binomial mixed-effects models adjusting for multiple comparisons. Representative heatmap of the average distribution scores of pSer129-aSyn immunoreactivity for each treatment group in varying brain regions in all the 9-month (p-q) and 21-month old (u-v) mice was generated in a sagittal mouse brain ( $n=10$ mice per group). Scale bars: $500 \mathrm{um}$.
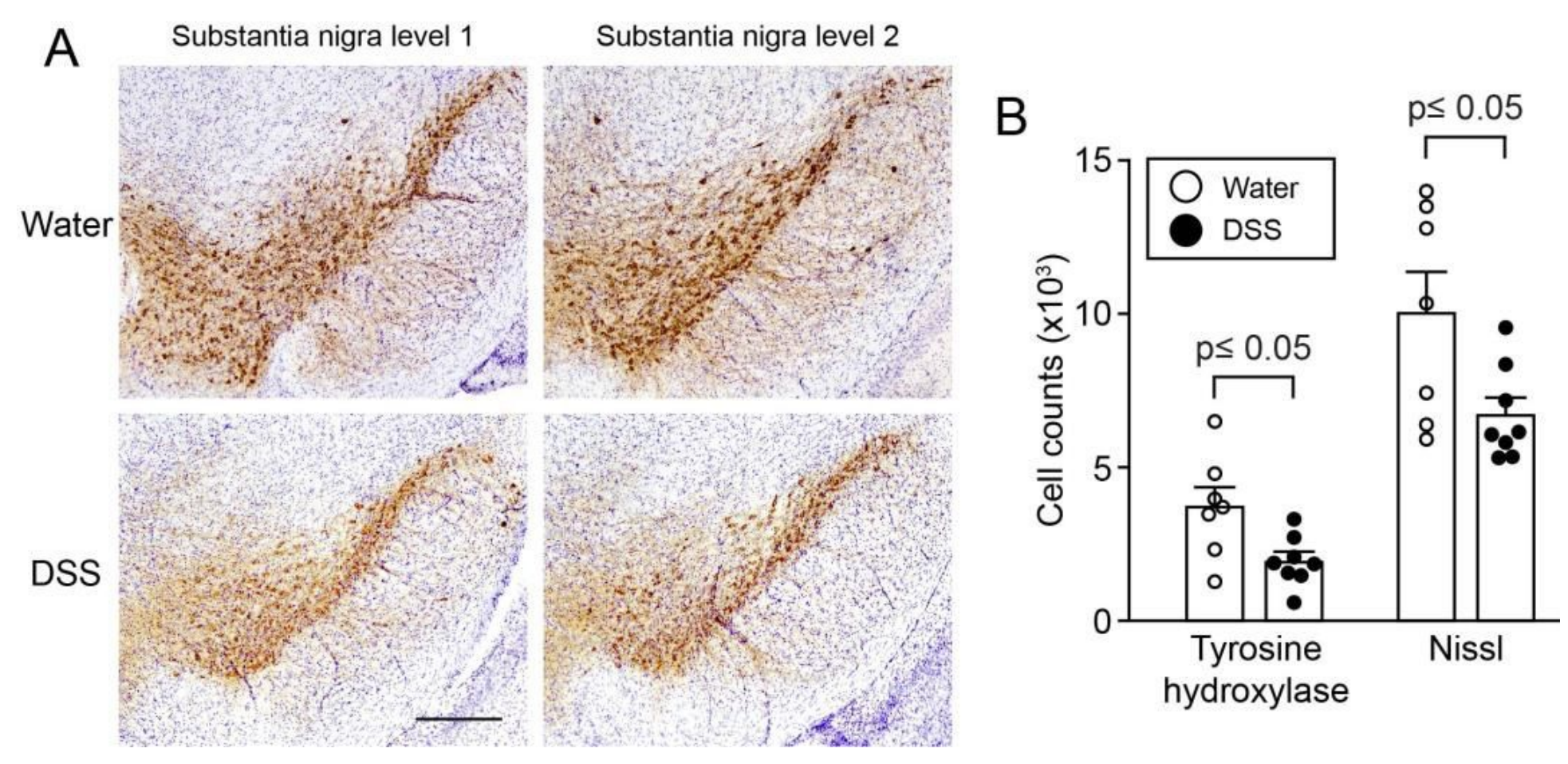

\section{Figure 6}

Loss of tyrosine hydroxylase and Nissl positive cells in the substantia nigra of (Thy1)-h[A30P]aSyn transgenic mice at 21 months of age, 18 months after DSS colitis. (Thy1)-h[A30P]aSyn transgenic mice that were exposed to a chronic DSS-colitis paradigm at 3 months and were aged to 21 months showed a significant loss of mean count of Nissl-positive cells with tyrosine hydroxylase (TH) immunoreactivity and cellular Nissl staining in the substantia nigra compared to age-matched littermate mice in the group that did not experience DSS colitis (water). a Representative Grathwohl et al. images of two levels of the substantia nigra in one mouse per group. b Stereological quantification of 1096 cells positive for TH or Nissl ( $n=7-8$ mice per group). Statistical analyses of the TH dataset were 1097 performed using Student's T-test, while Welch's T-test was used for the Nissl dataset to adjust for unequal variances. Scale bar: 500 um. 